\title{
The lived experience of being a hundred years and over
}

\author{
By
}

Ashwina Naiker-Ratan

A thesis submitted to Victoria University of Wellington in fulfilment of the requirements for the Degree of Master of Health Research

Victoria University of Wellington

2016 


\section{ABSTRACT}

The twentieth century has seen a decline in mortality after the age of eighty and an increase in survival rates of the oldest of the old. Centenarians (people over a hundred years of age) are the fastest growing group of this population in developed countries; however qualitative research on the oldest of the old is limited. The primary aim of this study was to gain an understanding of the essence of lived experiences and meanings of extended longevity as perceived by centenarians. It also aimed to explore the role of lifestyle characteristics, family, social, health and cultural factors in regards to their prolonged existence. The research was conducted with ten centenarians aged between 100 and 106 years living in the Lower North Island namely Wairarapa, Kapiti and Wellington of Aotearoa New Zealand. Biographical Narrative Interpretive Method of inquiry was used to guide the data collection through face-to-face interviews using unstructured open ended questions. Colazzi's phenomenological framework was employed for data analysis. There were common patterns throughout the life stories related by the centenarians and resilience and acceptance of life was notable. The centenarians spoke nonchalantly about their experience of turning a hundred, describing their birthday as; "Just another day." Positive personalities and resilient nature were prominent features of the participants who all expressed a sense of acceptance and satisfaction with life and contentment with living in the present. All centenarians had a privileged upbringing and were nurtured during their childhood by their parents, grandparents and siblings and these interrelationships were ongoing at an intergenerational level. They had all kept themselves active as much as they could throughout their lifetime. The results suggest that nurturing has an important role in the survival of the oldest of old. 


\section{ACKNOWLEDGEMENT}

I would like to thank all the centenarians who participated in this study and shared their stories with me. To my supervisor and mentor Dr. Kay de Vries, thank you for all your academic support and encouragement. My friends and colleagues; Joycelyn, Mary and the Prakash family, words cannot express my gratitude and appreciation for all your encouragement. A special thanks to Vera for your ongoing inspiration and guidance through my journey, without you and your newspaper clippings I would not have been successful in recruiting the participants. To my parents, Rita Devi and Armogam Naiker thank you for your unconditional love and support. I am appreciative of my In-laws Sarawati and Vidya Ratan for their understanding and assistance. I am very grateful to my husband Nilesh Ratan, thank you for being there for me and motivating me to continue with this research. To my two beautiful daughters Rhea and Lara, thank you for having patience and tolerance while I have been preoccupied with this study. I am grateful to Victoria University of Wellington staff and students for all their contribution. Also to Health Workforce New Zealand (HWNZ) and Hutt Valley District Health Board (HVDHB) thank you for providing me the opportunity to undertake this study through peer and financial support. 


\section{TABLE OF CONTENTS}

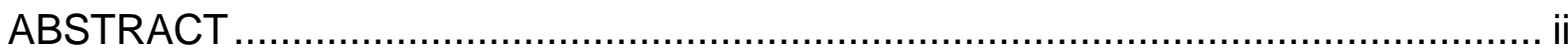

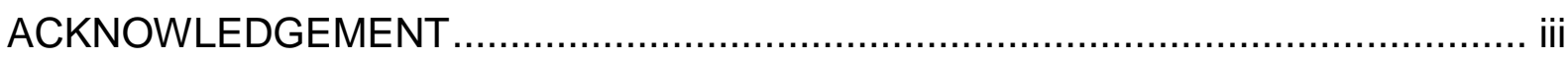

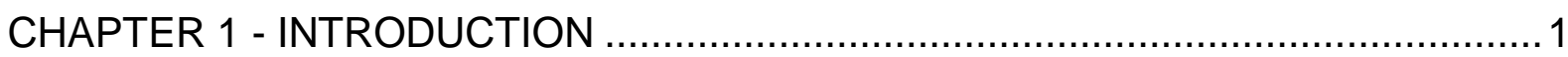

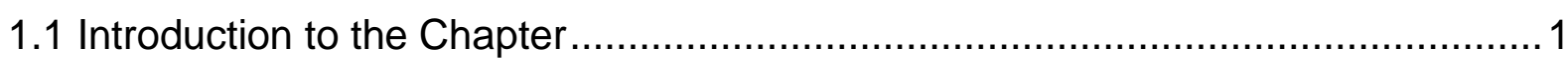

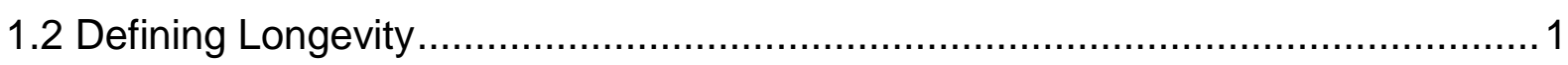

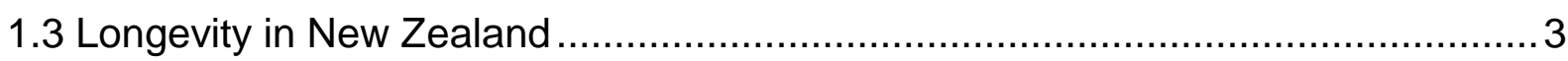

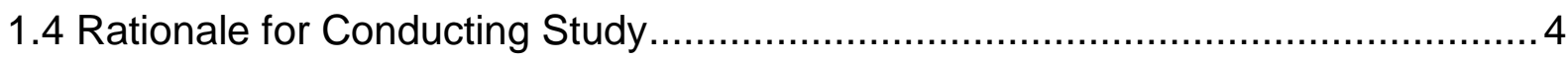

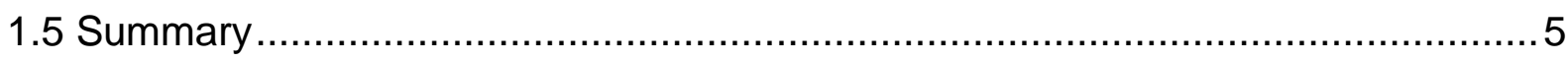

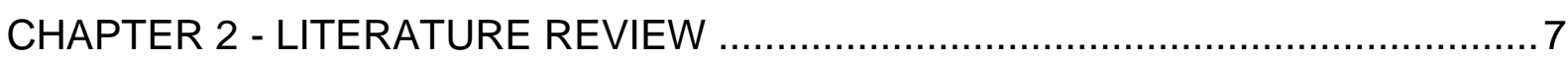

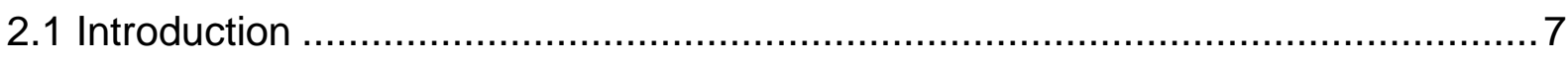

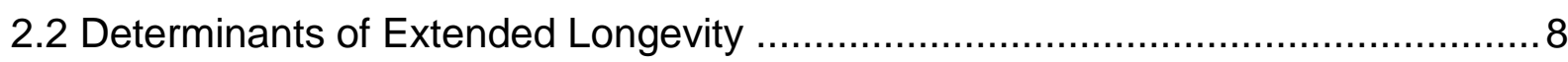

2.2.1 Gender Selection .................................................................. 8

2.2.2 Phenotypic and Genetic Association with Extended Longevity ............... 10

2.2.3 Non-Genetic Characteristics Associated with Extended Longevity .......... 12

2.3 Psycho-Social Theories of Ageing ......................................................... 14

2.3.1 Erikson's Psycho-Social Theory of Human Development....................... 14

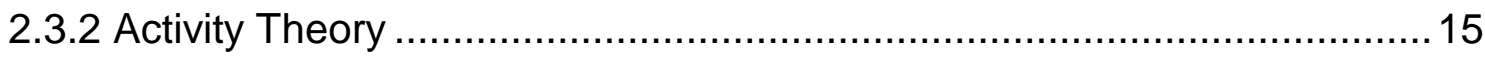

2.3.3 Disengagement Theory of Ageing ............................................. 16

2.3.4 Tornstam's Theory of Gerotranscendence .......................................... 18

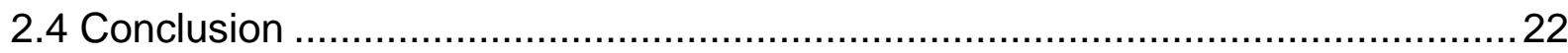

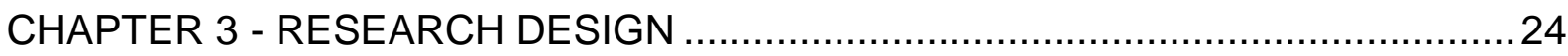

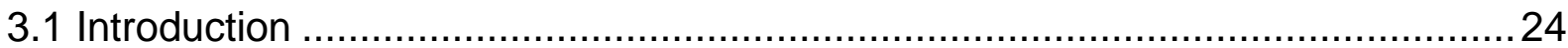

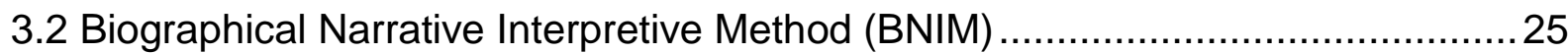

3.3 Methods of Sampling, Recruitment, Data Collection and Analysis .....................28

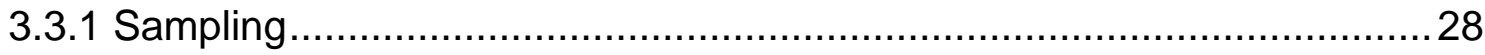

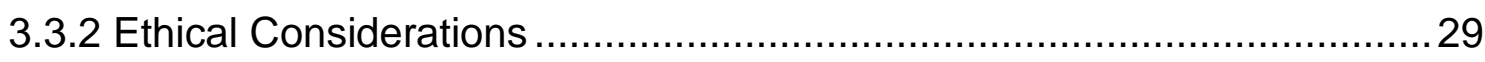

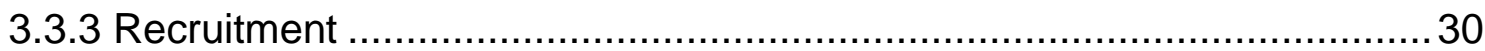

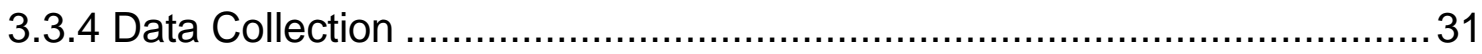

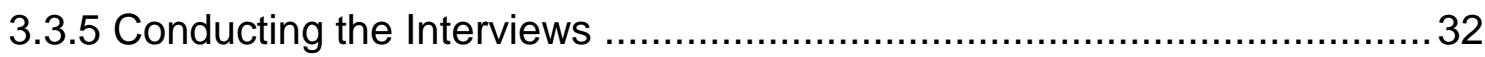

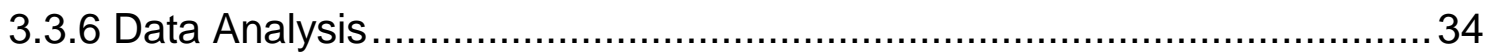

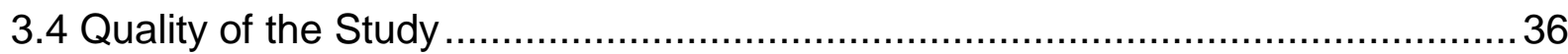

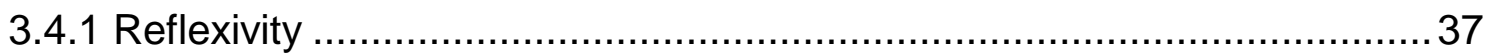

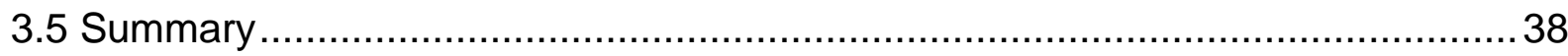

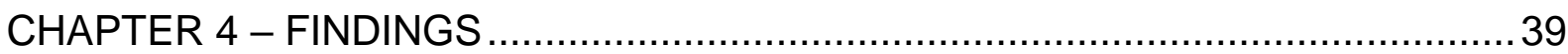

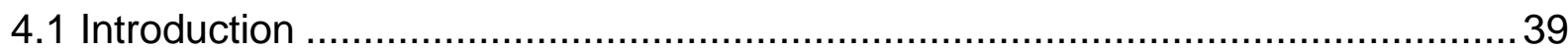


Figure 1: Diagrammatic depiction of the themes .40

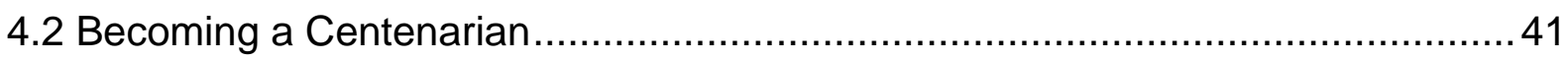

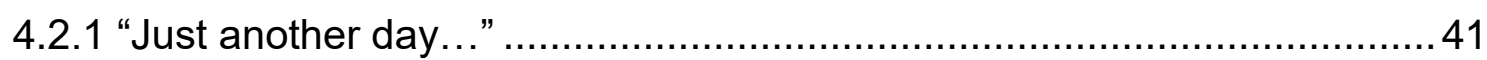

4.3 Growing Up in a Privileged Environment...................................................... 43

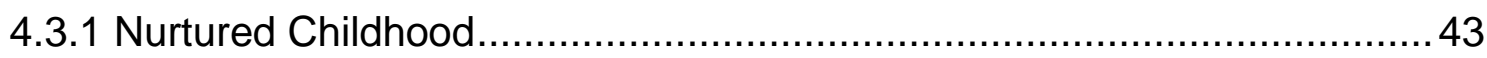

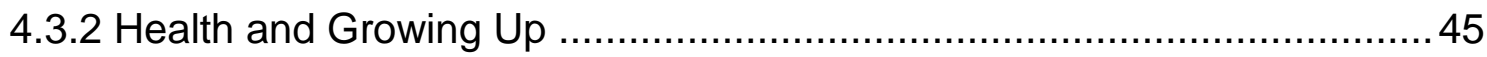

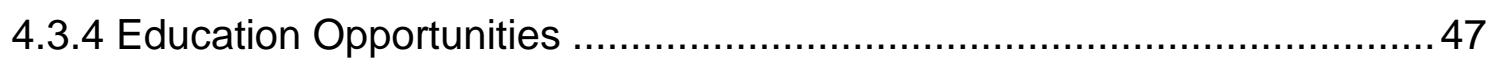

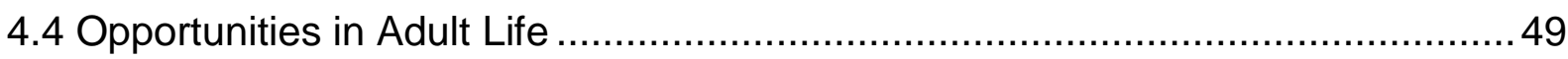

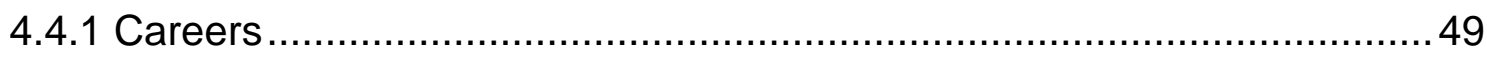

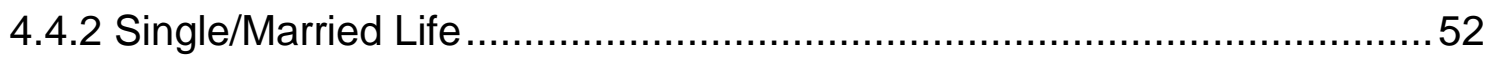

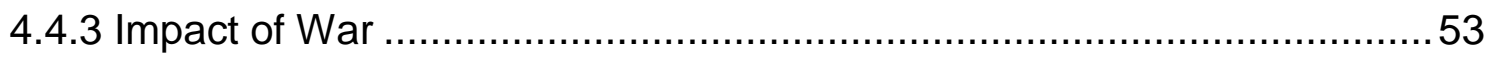

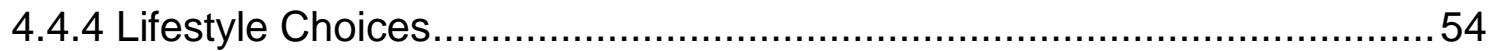

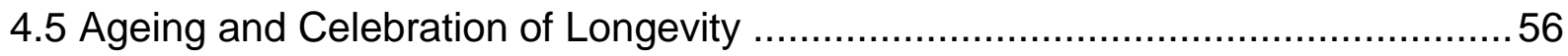

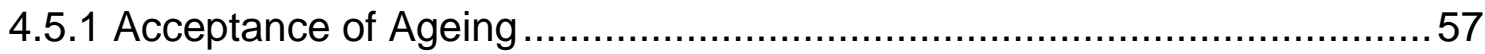

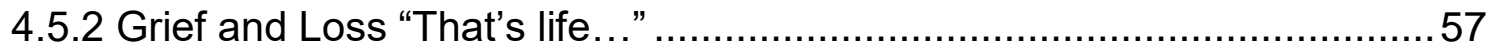

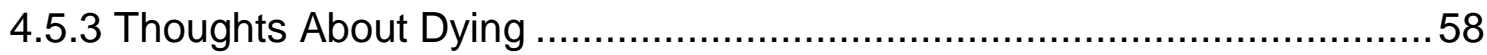

4.6 Generational Events... "A chance to get together" ..........................................59

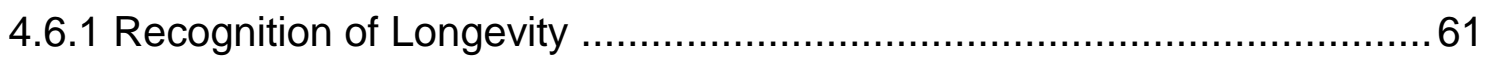

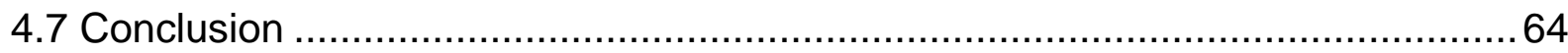

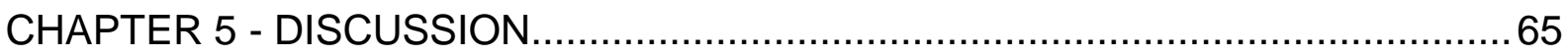

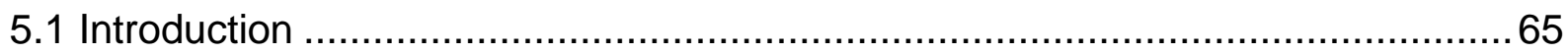

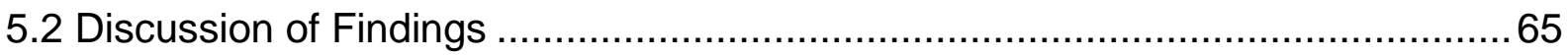

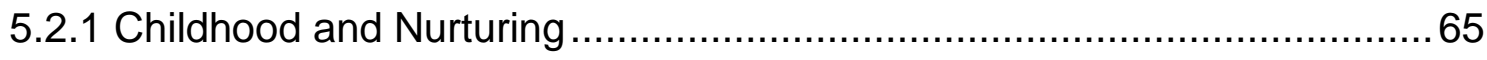

5.2.2 Stoicism, Resilience, Acceptance and Gender Bias ..............................68

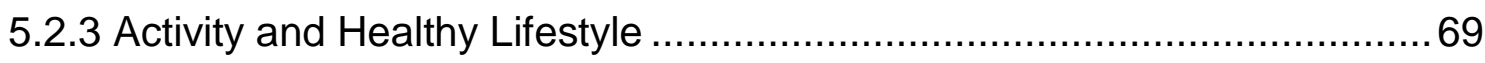

5.2.4Tornstam's Theory of Gerotranscendence ………................................. 69

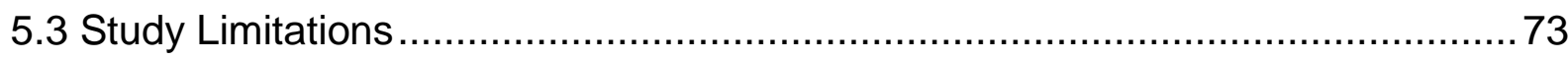

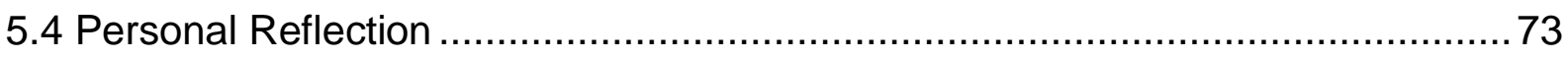

5.5 Implication on Practice / Education .......................................................... 74

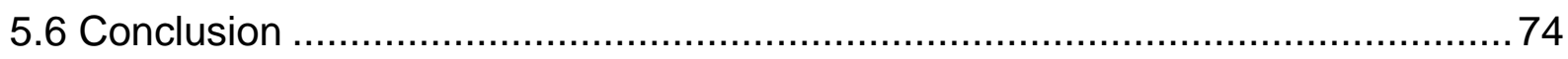

APPENDIX 1 An overview of Erikson's stages of psychosocial development and virtues associated with positive resolution of each crisis...............................76

APPENDIX 2 Participants Information Sheet............................................77

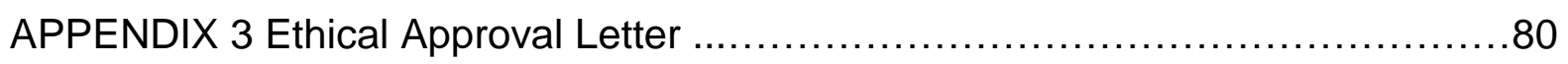

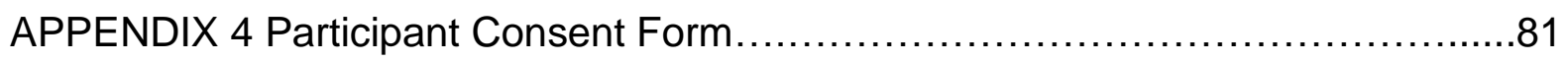

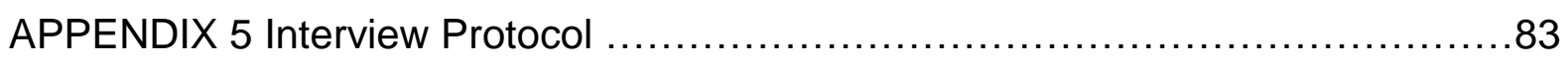


APPENDIX 6 Summary of Colaizzi's (1978) Method of Data Analysis................85

APPENDIX 7 Transcriber Confidentiality Form ...................................... 86

APPENDIX 8 An Example of Data Analysis and Coding.............................. 87

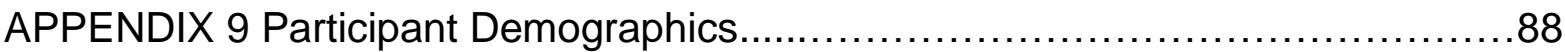

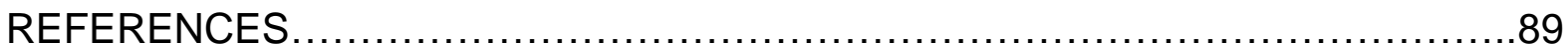




\section{CHAPTER 1 - INTRODUCTION}

\subsection{Introduction to the Chapter}

It is common knowledge that people globally are living longer than ever before. The global average life expectancy at birth is approximated at 70 years (Woodward \& Blakely, 2014). Females continue to dominate this trend and live an average of 5 years longer than their male counterparts (U.S Department of Health and Human Services, National Institute on Aging, National Institutes of Health, 2011). According to the World Health Organisation (WHO), the population of those people who are 60 years and over will double from 12 percent to 22 percent by the year 2050 (WHO, 2015). There are currently 125 million people aged 80 years and over, this is expected to increase to approximately 434 million by the year 2050 (WHO, 2015). It is predicted that around 80 percent of the 80 years and older population will be living in low and middle income earning countries as oppose to previous trends of increased number of 80 year olds and over living in developed countries (WHO, 2015).

The increase in average life span between the $19^{\text {th }}$ and $21^{\text {st }}$ century has been due to decline in childhood death rates (WHO, 2011). This decline is linked to improvements in living conditions such as sanitation, improved medical access and care, introduction of vaccines and discovery of antibiotics (Vina \& Borras, 2010). The introduction of antibiotics and vaccines has seen a decrease in infectious and parasitic diseases and an increase in non-communicable and degenerative disease (WHO, 2011). The rapid increase of the older population in developed countries in the $21^{\text {st }}$ century is due to a reduction in fertility rates and improvements in longevity (WHO, 2011). The rate of improved survival and reduced mortality rates in older age has been seen since the 1950 s, however it was not until the $20^{\text {th }}$ century that a lot of learning and research was conducted in this area (Vaupel, 1997).

\subsection{Defining Longevity}

Merriam-Webster online dictionary (n.d) provides a medical definition of longevity as: "A duration of an individual's life". Skytthe et al. (2003) states that extreme longevity is often of more interest to researchers and defines this as "Individuals who have survived 
past some certain age” (p.449). Skytthe et al. (2003) go further to state that the above definition is the simplest explanation of the term extreme longevity and it does not take into account factors such as gender and population shifts that are known to affect survival to such extreme age. According to the WHO (2011), the centenarian population is expected to increase 10 folds globally between the years 2010 to 2050 . The centenarian population has been classified into three categories depending on their age. A centenarian is a person who has reached the age of a hundred. Following this, the individuals aged 105 to 109 years have been called semi-supercentenarians and individuals aged 110 years and over have been called super-centenarians. Supercentenarians are a very rare group of individuals and the term super-centenarian is used for this group of individuals because they have reached an age that was previously stated to be unattainable (Willcox et al., 2008). Madame Jeanne Louise Calment who died on $4^{\text {th }}$ of August, 1997 in France is documented as the first person verified to have lived to a 122 years and 5 months (Lupien \& Wan, 2004; Robine \& Allard, 1998). The occurrence of this phenomenon was first noted in the 1960s with the super-centenarian numbers regularly on the rise since the 1970s (Robine \& Vaupel, 2001). More and more people around the world are not just reaching the milestone of turning a hundred, but are also more likely to live longer. These individuals are the fastest growing population age group in developed countries (Magnolfi et al., 2007; Terblanche, 2015). There are a number of reasons discussed in literature for this rapid growth in centenarian numbers. These include reduction in fertility rates, the reduction and sharp decline in infant and child mortality rates due to early detection and treatment of infectious diseases through accessible medical care, adequate and healthier living environments and good nutrition in developed countries. Vaupel (1997) has stated that the most important factor has been a decline in mortality after the age of 80 and an increase in survival rates of the oldest of the old. Female centenarians out number male centenarians as is the trend in general population (Terblanche, 2015; Vaupel, 1997). According to Terblanche (2015), although male centenarian numbers have been growing faster than female centenarian numbers, there is still a ratio of 19 male centenarians for every 100 female centenarians. Despite this gender bias, male centenarians have a greater compression of morbidity to end of life and therefore are better off cognitively and physically when compared to their female counterparts (Evert, Lawler, Bogan, \& Perls, 2003; Perls \& Terry, 2003). Understanding the trends of growth and needs of these groups of individuals is a vital step for health and aged care service planning and future policy developments. 


\subsection{Longevity in New Zealand}

New Zealand's current life expectancy at birth for females is 83.2 years and 79.5 years for males, both of these averages are above the Organisation for Economic Cooperation and Development (OECD) countries (Ministry of Health [MH], 2016). The sustained increase in life expectancy is due to public health advances, improved hygiene and more recently a reduction in smoking (Dulin, Stephens, Alpass, Hill, \& Stevenson, 2011; Ministry of Health, 2015). Despite this increase in life expectancy, there are a number of reasons provided in literature for the Māori and Pacific population not being able to reach extreme longevity (Dulin et al., 2011; $\mathrm{MH}, 2015 ; \mathrm{MH} 2016$ ). Comparing the gap in life expectancy between Māori and non-Māori in the 2013 census states that the average life expectancy of a Māori male was 73.0 years and Māori female was 77.1 years, when compared to non-Māori male 80.3 and non-Māori female 83.9 years for the same period $(\mathrm{MH}, 2015)$. The current data states that the Māori population is growing more rapidly than the non-Māori population. To put this into context, the Māori population is expected to grow by 16.2 percent whereas the nonMāori population is projected to grow by 13.5 percent between the year 2015 and 2030 (MH, 2015). Māori and Pacific experience poor health and have lower life expectancies than the population as a whole $(\mathrm{MH}, 2016)$. Overall, mortality rates are also higher for Māori than for non-Māori at nearly all ages (MH, 2014). This health disparity according to the $\mathrm{MH}$ (2016) is because Māori and Pacific people do not have the same benefits from health service as other New Zealanders. Māori and Pacific people are less likely to access primary health care services due to its associated cost $(\mathrm{MH}, 2016)$. $\mathrm{A}$ longitudinal study comparing New Zealand Māori and non-Māori population found that Māori scored lower on all measures being studied (formal education, level of activity and socio-economic status) than the non-Māori population (Dulin et al., 2011). This has also been supported by the $\mathrm{MH}$ (2015) which has provided data that states that Māori experienced more racial discrimination and increased numbers live in deprived situations which are both associated with poor health outcomes when compared to the non-Māori population. Poor health can also adversely affect people's education and employment opportunities ( $\mathrm{MH}, 2014)$. Poor health in the Māori population is also due to higher prevalence of smoking and alcohol consumption than the non-Māori population. Māori adults are three times more likely to smoke and twice more likely to consume large amounts of alcohol when compared to non-Māori adults $(\mathrm{MH}, 2015)$. 
These indicators show that Māori have poorer health status and outcomes compared to non-Māori, are more likely to be exposed to risk factors for poor health, and do not access primary care mainly because of cost. Apart from experiencing higher rates of disease conditions and chronic illness including cancer, diabetes, cardiovascular disease and asthma, Māori also have a higher rate of disability when compared to the non-Māori population (MH, 2015). The above factors associated with higher mortality rate and lower life expectancy for Māori population could explain reasons for Māori and Pacific people not reaching the age of hundred years and over. Statistics New Zealand (2013) census data states that on the night of the last census there were 561 individuals aged hundred years and over living in New Zealand. These figures do not differentiate between the Māori and non-Māori population. However, it can be stated that the majority of this group of the population is composed of non-Māori.

The primary objectives of this study was to understand personal experiences, perceptions and meanings of living to a hundred years and over. I also further explored the role of lifestyle characteristics, family, social, health and cultural factors in regards to their prolonged existence. When compared to the general population of $4,687,305$ living in New Zealand (Statistics New Zealand, 2013), the number of individuals aged a hundred years and over seems very small. Despite its small size this group of the population is growing at a considerable rate and therefore understanding and exploring their lived experiences will provide a new dimension and contribute to the body of research that is already present.

\subsection{Rationale for Conducting Study}

While there are numerous empirical studies on extreme longevity which have predominantly focused on biological factors that influence longevity (Dulin et al., 2011; Hensley et al., 2012; Kim, 2013; Miller et al., 2010; Sachdev et al., 2013; Sebastiani \& Perls, 2012; Rahman-Filipiak et al., 2015; Randall, Martin, McDonald, \& Poon, 2010), there is a paucity of qualitative research in regards to lived experience of being hundred years and over (Freeman, Garcia, \& Martson, 2013; Hutnik, Smith, \& Koch, 2012). I did not find any New Zealand research for the study of lived experience of the oldest of old. 
I started my nursing journey 12 years ago and over the years have developed a passion for gerontology nursing. Even as a novice nurse working in acute wards, being able to care for the older generation has been very fulfilling. When I was thinking of post-graduate study, I was always on the lookout for papers that I could do to improve my knowledge and practice in care of the older person. During my post-graduate diploma stage, I came across the Age and Ageing paper that was being offered at Victoria University of Wellington. This is when I met a 104-year-old female (Madeline) who I interviewed as part of the assignment for this post graduate paper. Her life story was so interesting that I decided to pursue other centenarian's experience of what it was like to turn a hundred. I found myself privileged to be able to spend time with individuals who have contributed to society and yet feel that they are ordinary individuals with very little to add and do not seem to feel that their story is worth being heard by anyone. My rationale for conducting this study was to be able to provide an understanding and appreciation for the lived experiences of the oldest of old in our society.

\subsection{Summary}

The aim of this study was to gain an understanding of the essence of lived experiences and meanings of extended longevity as perceived by centenarians and supercentenarians living in the Lower North Island namely Wairarapa, Kapiti and Wellington of Aotearoa New Zealand. I have provided a summary of the chapters below

Chapter 2- Literature Review: explores and critically reviews literature in regards to biological and psycho-social theories of ageing. I further explore factors such as nutrition, nurturing, socio-economic background and environment that influence living to extreme old age. There were a number of quantitative research studies available on the oldest of the old, however qualitative research on lived experiences of being or becoming a centenarian was limited.

Chapter 3- Study Design: presents the research method and design that I have utilised to guide this study. I examine the background and specification of Biological Narrative Interpretive Method (BNIM) of inquiry to guide this study (Wengraf, 2001; 2004; 2008). I further describe and discuss the methods of sampling, data collection and use of 
Colaizzi's phenomenological method of data analysis. I further discuss the quality of the study including reflexivity.

Chapter 4- Findings: I explore and provide meaning to the lived experiences of being a centenarian. There were five main themes that emerged from this study: Becoming a centenarian, growing up in a privileged environment, opportunities in adult life, ageing and celebration of longevity. These five main themes are presented in the findings chapter with the interlinked subthemes.

Chapter 5- Discussion: review the findings in relation to current literature, study limitations, recommendation for future research, education and implication for practice is also discussed. 


\section{CHAPTER 2 - LITERATURE REVIEW}

\subsection{Introduction}

The purpose of this chapter was to review the literature, firstly in preparation for carrying out the research and then in relation to my study findings. Extreme longevity has become an important topic of research for many in gerontology, with a growing number of quantitative studies in the field (Dulin et al., 2011; Hensley et al., 2012; Kim, 2013; Miller et al., 2010; Sachdev et al., 2013; Sebastiani \& Perls, 2012; RahmanFilipiak et al., 2015; Randall et al., 2010). Qualitative research studies on the oldest of the old is however rare (Freeman et al., 2013; Hutnik et al., 2012). Study of the lived experience of centenarians is a topic that needs wider exploration of the subjective and constructive meanings of extreme longevity in the oldest of the old.

The literature review was conducted in two phases. The initially phase of the review was to identify a breadth of academic references relevant to the study on oldest of the old. This phase was conducted to get an understanding of the research that has been conducted and to assist me with writing my research proposal and setting up for the study. The second phase of literature search was completed after the interviews were conducted, data analysed and themes drawn from the analysis. Electronic database CINAHL, PubMed, ProQuest and SAGE Knowledge were utilised during both phases of the literature review.

A common saying in gerontology is that we are data rich however theory poor (Schroots, 1996). There are multiple theories available that have tried to explain the biological and psycho-social aspects of ageing. Silverstein, Bengtson, Putnam, Putney, and Gans (2009) provides an analogy of these theories; "Theories are like lenses. Look at an object through one kind of lens, and the viewer will see one thing; look at it through another lens, and the viewer will be able to see something different" (p.5). There are two main categories for the theories of ageing: Biological ageing theories and psycho-social theories of ageing. The biological theories of ageing address the anatomic and physiological changes occurring with age. On the other hand, the psycho-social theories of ageing explain the thought processes and behaviours of the ageing person. 
This chapter starts with highlights from both contemporary and empirical research on possible factors that influence gender selection, genetic variation and centenarian phenotype on extended longevity; including research on nutrition, nurturing, socioeconomic background and environment influence on oldest of the old. Apart from biological theories, I also reviewed several different psycho-social theories of ageing that have evolved since the 1940s (Schroots, 1996) and provide a critique and have discussed various perspectives of the four psychological theories of ageing namely: Activity theory of ageing by Havighurst (1948); Erikson's (1950, 1968, 1982) psychosocial theory of human development; disengagement theory of ageing by Cumming and Henry (1961); and Tornstam's theory of gerotranscendence (Tornstam, 1989).

The above theories have been very widely used in the field of human development and ageing. The reason for using these specific theories in this study was based on the study findings. These theories provided a link and were consistent and reflective of the themes that emerged during data analysis and provide a framework and meaningful context to the study findings. I therefore, conclude this chapter with a summary and review of the main theories of ageing relevant to this study.

\subsection{Determinants of Extended Longevity}

There are multiple factors that influence extended longevity (Magnolfi et al., 2007). Researchers have robustly studied these since the $20^{\text {th }}$ century. There are common themes among most studies around reasons why people live longer. This includes gender selection, genetic and phenotypic variation and non-genetic determinants such as socio-economic background, education and nurturing.

\subsubsection{Gender Selection}

Females live longer than males (U.S Department of Health and Human Services, National Institute on Aging, National Institutes of Health, 2011; MH, 2016; Robine \& Allard, 1998; Terblanche, 2015; Vaupel, 1997) by a mean lifespan age of 4.2 years with a projected increase of 0.6 years by 2050 (Lunenfeld as cited in Eskes \& Haanen, 2007). There are a few reasons provided for this gender bias. Males have a three-fold higher risk of cardiovascular disease when compared to their female counterparts. This 
advantage is due to the increased production of oestrogen in females which has a suppressive effect on age related cells and protects against oxidative cell damage (Eskes \& Haanen, 2007; Vina \& Borras, 2010). Although the cardiovascular risk narrows in females with decrease in oestrogen levels related to menopause, women continue to have a better chance of reaching extended longevity when compared to their male counterparts (Franceschi et al., 2000; Magnolfi et al., 2009; Magnolfi et al., 2007; Vina \& Borras, 2010). Despite this longevity advantage, male centenarians are said to be better off in terms of cognitive and physical function when compared to females of the same age range (Perls \& Terry, 2003). Research conducted by Evert et al. (2003) found that male centenarians had a greater compression of morbidity at end of life when compared to female centenarians.

Compression of morbidity theory was developed by James Fries in the 1980s (Fries, 1980). The theory stated that there was a notable compression of age-associated diseases such as cardiovascular diseases, stroke, non-skin cancers and dementia to end of life. The idea behind this theory was that to benefit both the individual and society the period between the onset of disease to death should be shortened (Lupien \& Wan, 2004). This theory was tested by Evert et al. (2003) who found that the compression of morbidity theory was not completely reflective of individuals who have lived to a hundred years and over. Sebastiani and Perls (2012) found that although James Fries' theory on compression of morbidity was relevant from a delayed disability point of view, there was a mismatch of Fries' compression of morbidity theory to Evert's work. This could be because James Fries may have underestimated the limit of human life expectancy to extreme old age. Sebastiani and Perls (2012) tested Fries' compression of morbidity theory and noted in their study that individuals who had reached the age of 105 years and over had a much later onset of age-related diseases in both genders.

There are studies that have found that different factors may be responsible for the influence on extreme longevity in males and females. Magnolfi et al. (2007) found that female longevity greatly depended upon healthier lifestyle and favourable environmental conditions, whereas male centenarians' extended longevity was much more dependent on genetic factors. This was also evident in an Italian study of centenarians by Franceschi et al. (2000). 


\subsubsection{Phenotypic and Genetic Association with Extended Longevity}

There are numerous studies conducted on the influence of genetic and phenotypic composition on attaining extended longevity (Franceschi et al., 2000; Magnolfi et al., 2007; Schächter et al., 1994). These include but are not limited to studies on demographic selection, the longevity gene and the disease genes (Perls \& Terry, 2003; Schächter et al., 1994). Each study has tried to answer questions around why some people age slower than the general population and reasons for them being less susceptible to age related diseases (Perls \& Terry, 2003). According to Lupien and Wan (2004), there have been a number of studies that have examined centenarian phenotype to identify factors that affect extended longevity. These range from studies on body fat and metabolism, cardiovascular risk factors, immune and cognitive function in the oldest of old. They further state that none of these factors have provided enough evidence to link them strongly as influences of extreme longevity and therefore Lupien and Wan (2004) believe that genetic factors are the main predictors of extended longevity. These findings are debatable since a Scandinavian study of twins has found that 20 to 30 percent of average life expectancy is because of genetics and heritability and at least 70 percent was due to environmental factors (Ljungquist, Berg, Lanke, McClearn, \& Perdesen, 1998). Although in saying this, the Scandinavian twin study participant's average life expectancy was around 80 years of age therefore this study may have underestimated the genetic contribution to extreme old age (Willcox et al., 2006). In terms of extended longevity of centenarians, it can be argued that there is a genetic component that has a strong influence in determining extreme longevity as found in the New England familial study by Perl et al. (2002). They compared siblings of centenarians to siblings of non-centenarians and found that siblings of centenarians had a four times greater probability for survival to age ninety-one when compared to the non-centenarian group. This was similar to the results of the Okinawa centenarians and their siblings when compared to the general Okinawan population (Willcox et al., 2006).

Puca et al. (2001) linked a common gene known as chromosome 4 locus at D4S1564 among the centenarians and their family members in the New England study of 300 individuals who belonged to 107 sibships (a group of offspring having the same two parents). This was supported by Reed, Dick, Uniacke, Foroud, and Nichols (2004) study on male fraternal twins who also found that chromosome 4 locus at D4S1564 was associated with better physical health and longevity. Geesaman et al. (2003) also 
found a strong association between this gene and low risk of cardiovascular diseases in their study of American centenarians and near centenarians. Reduced cardiovascular risk in the oldest of old was also noted in Brazilai et al. (2003) study which found that high density lipoprotein (HDL) and low density lipoprotein (LDL) had a larger particle size in a sample of Ashkenazi Jewish centenarians and their off-spring. These larger particle sizes have been related to reduced risk of cardiovascular disease and hypertension and according to the study by Brazilai et al. (2003) this particular find is heritable and promotes healthy characteristics in individuals.

On the other hand, a significant genetic find has been the apolipoprotein $E € 2$ allele $(A p o E 2)$ gene which is highly prevalent in centenarians whereas in the general population the apolipoprotein $\mathrm{E} € 4$ allele $(A p o E 4)$ has been associated with premature mortality as it increases the risk of cardiovascular and Alzheimer's disease and to date is the most notable and consistent finding (Perls \& Terry, 2003; Schächter et al., 1994; Sebastiani \& Perls, 2012). The later gene (ApoE 4) was uncommon in centenarians who took part in this study. Genetic variation such as above yields findings that are significant in understanding extended longevity. This study has been critiqued for not having individuals of other ethnic backgrounds as they only had Caucasians as study participants. Willcox et al. (2008) also noted the Okinawa super-centenarians had a delay in the onset of major chronic diseases and had no clinical evidence of cardiovascular diseases until after the age of a hundred although there is no study of apolipoprotein $E € 2$ or 4 allele in this group.

In consideration of the above, Evert et al. (2003), has classified centenarians into three age-defined categories: the survivors, delayers and escapers. These categories define the age at which onset of age-associated disease were clinically evident. Age associated diseases for these classifications were cardiovascular disease, cancer, stroke, diabetes and dementia. Centenarians classified as survivors were less than 80 years old when they had an onset of at least one disease. Delayers were individuals who reported onset of disease between the age of 80 and 100 years. Escapers, as the name suggests, were individuals aged 100 years and over who did not have a diagnosed disease (Evert et al., 2003). Their study also found that when comparing the most common disease such as heart disease, stroke and non-skin cancer there was no statistical difference between males and females. According to Evert et al. (2003), most centenarians fit into the delayers category and coped with disease and 
were found to have a delay in the onset of disabilities related to diseases that increase the risk of mortality in the general older population.

There is strong evidence that familial components do contribute to extended longevity as evidence in the study conducted by Perl, Kunkel, and Puca (2002) on centenarian families in America. Willcox et al. (2006) study on Okinawan families also showed the survival rates were higher for family members of centenarians when compared with the general population of Okinawa. These studies suggest that genetic variations have an important role in achieving extended longevity. However, Magnolfi et al. (2007) argue that having adequate environmental and climatic protection such as improved technology, sanitation and higher socio-economic status yields better chances of survival to higher longevity than having particular selected genetic composition. Lupien and Wan (2004) also argue that genes should not be counted as the only major contributing factor in longevity as environmental and lifestyle factors also have been known to contribute to maximizing longevity.

\subsubsection{Non-Genetic Characteristics Associated with Extended Longevity}

People born in and after the $19^{\text {th }}$ century in a developed country have a better chance of survival to extended longevity than when born in earlier centuries. This is due to improved public health measures such as access to proper sanitation, cleaner water, medical advances and access to care, technology, introduction of vaccines and antibiotics have all improved survival rates of individuals (Sebastiani \& Perls, 2012).

Socio-economic conditions have been a factor that has had a significant influence on childhood survival rates. A study on African-Americans by Preston, Hill, and Drevenstedt (1998) during the $19^{\text {th }}$ century showed that there was a significant influence of childhood conditions such as environment and socio-economic status in predicting survival to advanced ages. However, when it comes to longevity, a Utah population study found that socio-economic status in childhood had a modest impact on extended longevity (Smith, Mineau, Garobotti, \& Kerber, 2009). This was similar to the findings in the Okinawan centenarians who have lower socio-economic status when compared to the rest of the Japanese population and have lived to extreme longevity despite this socio-economic disadvantage (Willcox et al., 2006). 
Elo and Preston (1996) have reported that educational achievements contribute to extended longevity. The reasons provided by these authors were based on the examination of educational attainment as a primary marker of socio-economic status and longer life. Studies have found that mortality of individuals decreased with every year of increased schooling due to increased health awareness in the educated group in regards to behaviours such as reduced or no smoking and increased exercise (Elo \& Preston, 1996; Lupien \& Lecours as cited in Lupien \& Wan, 2004). The link between formal educational attainment and longer lives is disputed by the study conducted on the Okinawa super-centenarians which showed no link between formal education attainment and longevity, as the Okinawa cohort did not have any form of formal education (Willcox et al., 2008). Extreme longevity in the Okinawa group was based on lifestyle, diet and genetic factors (Willcox et al., 2008).

Attaining extended longevity linked to lifestyle and region of residence was also found in an Italian study of centenarians (Magnolfi et al., 2007). More individuals survived to a 100 years and over in the northern and central region of Italy, which is near the sea and has favourable climatic conditions (Magnolfi et al., 2007). Fraser and Shavlik (2001), in their study of Californian Seventh Day Adventist, found healthy behaviours, such as diet, exercise and no tobacco or alcohol use, as dictated by their religion, increased their life expectancy by around seven years for males and four years for females when compared to the general white Californian population. Preston et al. (1998) found that growing up on a farm, presence of both parents increased childhood survival rates. His explanation for the improved chances of survival when living on a farm was because there was a reduced chance of contacting childhood infectious disease that were more common in densely populated urban areas.

Centenarians, although rare, are growing at a fast rate based on a combination of genetic variables, environmental and lifestyle factors which coexist to provide these individuals the most conducive and favourable elements to ensure survival to extreme old age. Perls (2007), after reviewing several studies on genetic variations and sociodemographic associations, came up with two key indicators at different stages of life; childhood and extreme old age, that affected extended longevity. Socio-demographic factors, such as environment and socio-economic factors, played an important role in survival during childhood years, however there was a strong indication that having a genetic advantage enabled individuals to live beyond just old age but survive to extreme old age (Perls, 2007). 


\subsection{Psycho-Social Theories of Ageing}

According to Lupien and Wan (2004), there has been a shift in views and perceptions of ageing over the last three decades. The shift from a negative age-stereotype, also known as ageism where ageing individuals were seen as being ill, isolated and a burden to society is now being challenged and replaced with a more positive and successful view of ageing (Lupien \& Wan, 2004). The change in perception from ageism to successful ageing was in the late half of the $20^{\text {th }}$ century due to an increase number of older people in developed countries. More and more individuals are living longer, healthier and happier lives, their contribution to society can no longer be ignored or seen in a negative light. Also this global increase in the ageing population has increased interest in researchers to investigate not just physical but psycho-social factors that affect and influence the older person (Wang et al., 2015).

\subsubsection{Erikson's Psycho-Social Theory of Human Development}

Erik Erikson was a German born American psychoanalyst who developed a theory on human psycho-social development. His model consists of a series of eight crisis called psycho-social stages that characterise human personality development. Erikson viewed crisis in a positive connotation, as crisis according to him is viewed as a challenge or internal conflict that provides an opportunity for personality growth (Svetina, 2014). According to Erikson $(1963,1982)$ facing and successfully resolving a crisis is a key indicator of psycho-social developmental and maturation in an individual. The eight psycho-social stages are specific to certain periods of life and are defined as follows: trust versus mistrust (infancy), autonomy versus shame (early childhood), initiative versus guilt (play age), industry versus inferiority (school age), ego-identity versus role confusion (adolescence), intimacy versus isolation (young adulthood), generativity versus stagnation (middle adulthood), ego integrity versus despair (old age). Appendix 1 provides an overview of Erikson's stages of psychosocial development and virtues associated with positive resolution of each crisis.

Erikson's psycho-social theory has been widely used as one of the most influential and well known theories of human development (Merriam, Courtenay, \& Revees, 1997). A number of researchers have also used part or all of his theory as a springboard to generate newer theories which are pertinent to their specialty of psycho-social 
development (Tornstam, 1989; Vogel-Scibilia et al., 2009). Eriksonian theory provides a platform for understanding the complexities of positive and negative influences of culture and society on the developmental stages of the ego, super-ego and personality. However, it has been argued that Erikson's work on the identity stage has been used narrowly and restrictively as many researchers have acknowledged it as only pertinent to a specific time and stage of development and in a more linear fashion rather than as a continuous and evolving lifelong process (Cote \& Levine, 1987). Critics have also highlighted that Erikson's stages of psycho-social development do not fully account for racial, gender or ethnic issues as his theories are based on examination and research on developmental behaviour in white individuals in the 1960s (Vogel-Scibilia et al., 2009). The largest proportion of Erikson's study and explanation was based around the childhood and adolescence stages of development (Merriam et al., 1997). Furthermore, although Erikson's theory on childhood psycho-social development is a comprehensive approach, it has been based on the western world view and does not adequately reflect childhood development in under privileged societies, for example, active war zones (Ramdhan, 2010).

Erikson's work on childhood and society was published post the Second World War, in 1950. It covers a range of psychological and social factors that can have an impact on the development of ego and personality of a child however it does not cover the impact of war on psycho-social development. According to Merriam et al. (1997) Erikson's stages of development do not address terminal illness and how one might move through these in their end of life, especially if they are a younger person. Erikson's theory has also been criticised by Hergenhahn (1994) for its "Excessive moralizing", its "Support of the status quo" and its "Overly optimistic view of humans" (p.189). Also, according to Thomas and Eisenhandler (1994), Erikson's theory does not incorporate religious dimensions. They have also commented at the vagueness of Erikson's eight positive psychosocial stage of wisdom.

\subsubsection{Activity Theory}

Activity theory has been referred to as the oldest known and documented theory of ageing (John, 1984; Schroots, 1996). Activity theory theorised that there was a link between life satisfaction and level of activity on an individual. The theory suggests that, as the level of activity decreases so does the life satisfaction of an individual (Chen, 
2003). Critics claim that this theory did not take socio-economic status and health disparities into account that may be major factors and reasons for the decline or diminished opportunities in the older person. According to John (1984), this theory remained as more of an assumption until challenged about its explicitly by Cummings and Henry in 1961 and was disputed and replaced by the theory of disengagement.

\subsubsection{Disengagement Theory of Ageing}

The early negative view of ageing provided for the disengagement theory that portrayed ageing and the process of ageing as individuals socially disengaging from personal relationships and society (Lupien \& Wan, 2004). Based on their argument about the lack of work on theories for older people, Cumming et al. (1960) conducted a study on 211 participants between the ages of 50 and 70 years of age. The results of the study lead them to develop a tentative theory of ageing in which the older person is in a disengaged state. Cumming and Henry in 1961 went on to write a book called 'Growing old: The process of Disengagement', to compensate for the paucity of ageing theories (Chen, 2003). Cumming and Henry (1961), proposed that; "Aging is an inevitable, mutual withdrawal or disengagement, resulting in decreased interaction between the aging person and other in the social system he belongs to" ( $\mathrm{p} .14)$. The disengagement theory proposes that as humans age, they sever their interests with social activities. The theory also takes the position that, as individuals age, there is a reduction in knowledge, skills and abandonment of life's central roles. Successful ageing based on this theory means disengagement rather than engagement between the individual and society (Cumming \& Henry, 1961; Johnson \& Barer, 1992). Reduced interest in engaging in social activities for older people has also been linked to a reduction of social networks due to death of close friends and deterioration of physical health (Johnson \& Barer, 1992).

Disengagement theory has been rejected and criticised by many researchers for its misinterpretation of the ageing process especially as ageing is given a slightly negative connotation (Johnson \& Barer, 1992). In response to the critics, Cumming and Henry revised this theory in 1963 (John 1984). In 1963, Cumming published another article called: 'Further thoughts on the theory of disengagement'. In this article, Cumming states that the original theory of disengagement did not have sufficient detail. Cumming's intentions of rewriting this theory was to point out that not all ageing 
individuals will experience disengagement and an individual's ability to deal and cope with life events such as retirement or loss of spouse can promote either the process of disengagement or engagement with self and society (Cumming, 1963).

In contradiction to the disengagement theory, research by Johnson and Barer (1992) found a correlation between staying physically active and retaining an active continuity in social life leads to good mood and is reflected and associated with engagement rather than disengagement. Johnson and Barer (1992) also found that those that disengaged, did this on purpose by modifying their social regime due to physical loss of function and regulated or paced their daily social activities so that they had better energy conservation. The older people had energy for activities and relationships that held meaning and were more important to them.

The theory of disengagement created three hypotheses; the first being that society rejects older people and according to Tornstam (1989), gerontologists were in agreement that western society did indeed push older people aside and in a way rejected them. However, the theory of disengagement did not take into account other cultures that look after their older people and find them to be a source of great wisdom.

The second hypothesis stated that the older people themselves disengaged from their social roles by declining their involvement in society and activities (Cummings \& Henry, 1961). This was dismissed by many researchers as there was no credible evidence to support this hypothesis (Tornstam, 1989). As people get older they often tend to decrease their social circle and maintain relationships that are deep and have more meaning (Helmuth, 2003), however, loneliness is at times interpreted as a pathological issue due to its association with diseases such as depression, self-doubt, anxiety, insecurity (Thomas \& Eisenhandler, 1994). Loneliness is very subjective and is dependent on an individual's interpretation (Patterson \& Veenstra, 2010). The older person living alone does not constitute loneliness and social isolation as most of them have close social networks in the form of family and friends. "Older people value their privacy and consider living alone an achievement, not a sign of rejection" (Thomas \& Eisenhandler, 1994, p.16). It is the quality of these relationships not the quantity that enables a significant difference in decreasing loneliness.

The third hypothesis of the disengagement theory was around the older person's satisfaction and contentment at later stage of life. This has generated interest and has led to formulation of theories such as the gerotranscendence theory to further explain 
this phenomenon. To better understand the phenomenon of ageing, Tornstam decided to use a phenomenological approach rather than a positivist one and through this formulated a theory of gerotranscendence. Tornstam (2005) later tested his theory of gerotranscendence using a positivist approach (Tornstam, 2005). Although Tornstam initially disregarded the theory of disengagement like other gerontologists, he later, through his own personal experience came to an understanding of its explanatory power. Tornstam does not explain the 'intuitive feelings' that led him to this position but he does agree with the third hypothesis of the disengagement theory and in exploring it further arrived at his own theory of ageing; the theory of gerotranscendence.

\subsubsection{Tornstam's Theory of Gerotranscendence}

Lars Tornstam first developed the theory of gerotranscendence in 1989 (Tornstam, 1989). He initially tested his theory through in-depth interviews with 50 individuals between the ages of 50 and 97 years of age (Tornstam, 2005). His theory on gerotranscendence has tried to cover the gaps or 'blind spots' that older theories, such as activity and disengagement theory, have not comprehensively covered about the ageing paradigms (Tornstam, 2005). Tornstam's provides a means of understanding the transcendence into old age from a different prospective and in a newer light with empirical backing (Tornstam, 1994). Tornstam further developed his theory of gerotranscendence after interviews, letters and emails from individuals who had sensed a level of gerotranscendence in their lives after attending seminars conducted by Tornstam in 1991 (Tornstam, 2005). His way of formulating this theory was to reverse the research methodology so that the participants of the study were the ones providing the theoretical framework for his theory of ageing. According to Tornstam (2005), he has presented a set of ideas and concepts that are unfamiliar and unscientific in the western world. Concepts such as mystical, meditation and cosmic communion have been used throughout his book.

Gerotranscendence has been described by Tornstam (2005) as a "Shift in metaperspective from a materialistic and rational perspective to a more cosmic and transcendent one. This is more normally followed by increase in life satisfaction"(p.41). Tornstam (2005) states that the theory of gerotranscendence provides a phenomenological understanding of an individual's subjective meanings of inner self 
and perspective of their live. Tornstam (2005) further states that the development towards gerotranscendence may be accompanied by the following:

- Increasing feeling of cosmic communion with the spirit of the universe

- A redefinition of the perception of time, space and objects

- A redefinition of perception of life and death and a decrease in the fear of death

- An increased feeling of affinity with past and coming generations

- A decrease in interest in superfluous social interaction

- A decrease in interest in material things

- A decrease in self-centeredness

- An increase in time spent on mediation. (p.41).

Tornstam describes the above as the individual having a more cosmic view and sees oneself as an integrated part of the universe. The individual who has reached this level of gerotranscendence does not have an interest in materialistic and superficial items but spends more time in meditation. They (older people) also have pity on the youths and middle aged adults who put excessive emphasis and importance on materialistic, trivial objects and work engagements (Tornstam, 2005). They have an increased affiliation with the former, present and coming generations. The boundaries between the past present and future are erased and according to Tornstam (2005) a person who has transcended to a higher meaning of life has increased satisfaction with life and decreased fear of death. This is similar in many ways to the stage of ego-integrity in Erikson's theory where the older person acquires a personality characteristic of wisdom. Tornstam himself admits that his theory of gerotranscendence can be very closely related to Erikson's final and eighth stage of human psycho-social development .Tornstam also found that the process of gerotranscendence can be accelerated by meditation or a life crisis, such as having a life threatening or terminal illness (Tornstam, 2005). The process of gerotranscendence can also be obstructed by making the older person take part in activities and social engagement. This is due to the common belief that the older person is withdrawn and therefore his or her behaviour is associated with negative disengagement (Tornstam, 1989).

Tornstam's (1997) theory of gerotranscendence states that the individual is in a constant motion of development and change towards a more cosmic view of life. Researchers have noted that older individuals, who have reached this stage of transcendence, often talk about redefining their self, their personality and relationship 
to others (Tornstam, 1997). This theory is not about ageless self but more about the development, re-definition and rediscovery of self to a more cosmic level of thinking and understanding. Read, Braam, Lyyra and Deeg (2014) tested the effects of negative life events on gerotranscendence and found that negative life events, especially events other than the death of others, was related to increased gerotranscendence, more specifically with increase in cosmic transcendence. Read et al. (2014) and Wang et al. (2015) also found that older male participants had lower reported levels of gerotranscendence when compared to older female participants. In their study of Chinese older people, Wang et al. (2015) found that being an older female, regular physical activity, religious affiliation and living arrangements in China were associated and had an influence on achieving higher level of gerotranscendence.

Tornstam has argued that the western values of effectiveness, productivity and rationalism has lead one to view ageing as a negative phenomenon. This theory provides a positive paradigm of ageing and encourages readers to see ageing in a positive light. What has been viewed so far as disengaged and withdrawn by earlier theories has been provided with a different meta-perspective. It has enabled us to view ageing from a different standpoint and regard an older person differently, one that views all stages of ageing in a positive light and is accepting of the older person's decreased involvement in society and increased interest in alternate activity in the form of contemplation and meditation (Tornstam, 1994).

The gerotranscendence theory has many implications for health care providers, where there is currently a need to ensure older persons are engaged in activity. With application of this theory health care providers may view the older person as going through the gerotranscendence phase and therefore not requiring reactivation. In some cases, this may be accurate while in others this may lead to pathological changes such as depression not being recognised. Tornstam (2005) has warned against misuse of this theory and has stated that each older person should be viewed on the basis of their own merit and that for some people other theories of ageing may be more applicable. His theory is based on eastern culture and he has denounced the western culture as not allowing this process of gerotranscendence to take place due to its values and beliefs being based around productivity and efficiency (Tornstam, 2005). There is a danger that excessive use and misinterpretation of this theory may promote social isolation, physical decline and complications due to less physical and emotion involvement with others (Tornstam, 1994). Tornstam has also warned against 
misinterpreting the signs of depression and mental illness and has agreed with his critics who have stated that the signs of depression or mental illness can be easily mistaken for an individual being in a state of gerotranscendence. The use of various psychotropic drugs could also produce the same state that Tornstam has described as, the cosmic and ego transcendence (Tornstam, 1994).

One of the other critiques of the theory of gerotranscendence has been the lack of concrete guidelines provided by Tornstam on how to use this theory in practice (Wadensten \& Carlsson, 2002; Wadensten \& Carlsson, 2007). To understand the behaviours exhibited by the ageing person in light of the theory of gerotranscendence, Wadensten and Carlsson (2001) conducted a study on nursing staff members working with older people in a Sweden nursing home to investigate whether nursing staff members could recognise and interpret the signs of gerotranscendence. They also investigated how the nursing staff members cared for the older person when signs of gerotranscendence were recognised in these older people. Staff members who took part in this study were not familiar with the theory of gerotranscendence prior to the interviews. Wadensten and Carlsson's (2001) study found that there was a great deal of variation in regards to staff members' interpretation of behaviours in the older person. They categorised staff members' interpretation of the older person's behaviour into three main themes: pathological, invisible and normal. Some staff members interpreted the older persons' change in perception of time and space as either the older person had dementia or showed signs of confusion (pathological), even though some staff noted the older person reflected on their earlier life, staff did not think that it was anything unusual (invisible), the older person who showed decreased interest in material things and talked about their childhood as normal part of the ageing process (normal). This study found that nursing staff members did not know how to care for or interact with the older person who showed signs of gerotranscendence. Wadensten and Carlsson's (2001) further state that having an interpretive framework and guidelines would enable the staff members to develop better understanding of gerotranscendence signs that they observe in older people and provide them with another approach to care for the older person.

In light of the lack of guidelines available on the theory of gerotranscendence Wadensten \& Carlsson, (2002); Wadensten \& Carlsson, (2007) used a focus group approach to derive guidelines for practical care of the older person to promote development towards gerotranscendence and provide care for the older person who 
has already approached gerotranscendence. Wadensten (2005) also conducted a study using group sessions with women aged between 68 and 80 years living in a nursing care centre in Sweden. The aim of Wadensten's (2005) study was to introduce participants to the theory of gerotranscendence and to discuss the ageing process and their ageing in relation to the theory. Wadensten's study found that participants felt positive about themselves and their ageing process after being introduced to the theory of gerotranscendence. All participants in this study found it beneficial as it provided them with a great meaning and understanding of the ageing process and were able to see their ageing in a positive light.

\subsection{Conclusion}

Extended longevity is a highly dynamic phenomenon with multiple researchers trying to understand the effects of nature and nurture on extended longevity. Despite this ongoing debate there is some consensus among researchers that factors associated with extended longevity is multifactorial and requires further ongoing research in this field. Studies and hypotheses on biological reasons for attaining extreme longevity have come to the conclusion that genetics has a role to play in extending life and that genetically favoured individuals have a better chance of reaching extreme old age. Apart from biological studies of ageing, there are a number of psycho-social theories of ageing that have been developed over the years. Some of these theories have been left as assumptions while others are more frequently applied to the ageing process. Each theory aims to explain the implication and meaning of growing old. They have all, to some extent, tried to incorporate the effects and influence of socio-economic status, physical, mental health and relationships with others.

The early theories of ageing, such as the activity theory and disengagement theory have little or no documented evidence around how different country's political and economic scenes, cultural values, religious beliefs and events such as wars can capture the stages of ageing in a holistic manner. Also earlier theories were based on assumptions and studies that were conducted on a backdrop of the American society of a certain historical era. These unintentional assumptions of homogeneity have resulted in restricting the application of these theories outside of the social structure that they were tested and studied in. Also the lack of guidelines on how to apply these theories in the care of the older person has left gaps between theories and applying 
this to practice. Tornstam's theory on the other hand is based on eastern culture and does not take much consideration of the western culture and its influence on ageing process. Ageing should therefore be seen from a multidimensional point of view. The theories that are applied, understood and accepted in relation to the behaviours displayed by an older person depend on the position, views and perspective of the person studying them.

The next chapter presents the research design, I have also discussed the methods of sampling, data collection and use of Colaizzi's (1978) phenomenological method of data analysis. The quality of the study including reflexivity are also discussed in Chapter 3. 


\section{CHAPTER 3 - RESEARCH DESIGN}

\subsection{Introduction}

This chapter focuses on the research principles I employed to guide the study. Quantitative and qualitative research have distinct features that need careful consideration when choosing the best research approach for a study. Understanding specific features of each approach ensures application of the most suitable methodology to a study.

Quantitative research promotes the discovery of quantifiable information. This research focuses on measurable phenomena and is normally associated with a positivist and objectivist stance (Bryman, 2008). Data analysis and presentation of findings is in an empirical format. The basis of this research is on objective theories and statistical evidence (Ingham-Bloomfield, 2014). Conversely, qualitative research approaches look into the social life of people and produces words as data rather than numbers and figures. It typically takes an interpretivist and constructionist stance. According to McCusker and Gunaydin (2015), the purpose of qualitative research is to explore the subjective meanings and interpretation of life experiences and journeys of individuals. Qualitative research, also known as naturalistic inquiry, offers a chance for researchers to explore and study human experiences.

The paradigm debates between qualitative and quantitative research are characterised by epistemological and ontological positions. Choices about paradigms and research frameworks are influenced by the phenomenon under investigation (Bryman 2008; Grix 2002; Sarantakos 1993). In this chapter, I rationalise the use of the qualitative approach (Biographic-Narrative Interpretive Method) that I utilised to guide the study. I provide my reasoning for the choice of the research approach, its benefits and limitations to this study. I also outline the methods of sampling, recruitment, data collection and data analysis. In addition, I discuss the credibility, transferability, confirmability and my reflexivity in relation to this study.

This study aimed to gain an understanding of the essence of the lived experiences and meanings of extended longevity as perceived by centenarians and super-centenarians. The primary objective of this study was to understand local and personal experiences, perceptions and meanings of such extended longevity. I also wanted to explore the 
role of lifestyle, family, social, health and cultural factors in relation to their prolonged life.

\subsection{Biographical Narrative Interpretive Method (BNIM)}

I had initially intended to carry out a descriptive phenomenological study focusing on the 'lived experiences' of my participants on reaching the age of a hundred. Early stages of data collection revealed that participants did not want to talk about their experiences of being a hundred, they were more eager to narrate and have someone listen to their life stories. Telling their life story, for the older person, was a way of connecting with their past and reliving memories that held significant importance in their lives. According to Haight (2001) and Rosenthal (2003), a life review is the final psychosocial stage of wisdom and peace as this can bring the older person closer to integrity. It also has a healing and emancipatory effect on an individual's life. In her book, The Art of Storytelling, Nancy Mellon (1998) states, "Because there is a natural storytelling urge and ability in all human beings, even just a little nurturing of this impulse can bring about astonishing and delightful results" (p.174).

Many factors influence telling of a life story, the subsequent relaying of that story to others and its interpretation. As a researcher entering their world and their experiences, I realised the topic that I wanted to explore with the participants was not what the participants wanted to share with me. Participants' views of subjective realities were providing shape to my research framework. I therefore changed my study design to include using BNIM to more accurately reflect participants' life stories.

Biographical method originated in Germany and was further developed by the sociologist Frits Schutze. There is debate about the period of its origin. Some literature state that the biographical turn was in the 1970s while others state that it was in the 1980s (Bornat, 2008; Rosenthal, 1993). The 1990s saw a burgeoning interest in biographical narrative method of inquiry and the use of narrativity in gerontology in social science research. Its rise was because of researchers' findings not adequately representing full accounts of the shifting power bases between individual agency and the structural determinants in societies (Chamberlayne, Bornat, \& Wengraf, 2000; Chamberlyane \& King, 2000). Chamberlayne and Wengraf further developed this method in the early 2000s (Jones, 2002). The main distinguishing feature of this 
approach within the broad and rich range of life history and narrative approaches is that it places emphasis on action and latent meaning (Jones, 2002). It acknowledges the pervasive nature of interpretivism by recognising the subjectivity of participants and its interpretation by researchers. Biographical narrative interpretive method's core assumptions are intentionally broad based. This method considers the entire life story of an individual or group of individuals both by its beginning and construction in the present (Rosenthal, 2003). It is used to interpret historical, social and biographical stories of peoples' lives (Corbally \& O'Neill, 2014). The analytical strategy that is adopted endeavours to analyse three interrelated facets of humanity: biography (person's life story); narrative (how he or she tells it); and interpretation (constructions of meanings and social interpretation) of individual life stories (Corbally \& O'Neill, 2014).

This approach encourages narration of biographical experiences according to how the participants feel and what they find relevant. It assists to explore reasons for individuals' narrating their life stories in the way they do (Corbally \& O'Neill, 2014). BNIM enables a reflection on nuances of human experiences as they play out in the individuals' consciousness and without this sensitivity, the story and the analysis would be incomplete (Ross \& Moore, 2014). This methodology is different from other narrative methods in that it aims to draw and interpret narratives for qualitative analysis and evaluation. This is achieved by comparing individual subjectivity of 'the lived life' and the 'told story' and focusing on discrepancies between self-understanding and behaviour (Chamberlayne et al., 2000; Wengraf 2001). Key advocates of this method claim that narrative approaches of this kind signal 'A 'subjective' or 'cultural turn' - in which personal and social meanings as bases of action gain greater prominence" (Chamberlayne et al., 2000, p.1).

Biographical narrative interpretive method uses a three-part interview process, also called sub-session one, two and three (Wengraf, 2004). It has a specific interview technique; the interviewer asks a single question and facilitates an open response. To enable the biographers to provide more detailed narration, the interviewer uses paralinguistic cues such as, intonation, body posture, gestures, and facial expression that modify the meaning of verbal communication. This ensures the narration flows effortlessly as participants feel encouraged to tell their stories without interruptions. Interview for this approach, when carried out accurately, promotes ease of telling their 
stories (Rosenthal, 2003). This interview process is discussed in more detail later in the interviewing section of this chapter.

Biographical narrative interpretive method completes data analysis by use of a panel (Wengraf, 2001). Use of a panel was not made for this study due to the nature of the research as an educational activity. It would have also been difficult to access a panel due to time constraints and lack of availability of appropriate personnel. I have therefore employed the use of Colaizzi's (1978) phenomenological framework for data analysis. The use of phenomenological approaches to analyse narrative life story data has been used by other researchers (Clare et al., 2008; Dickenson et al., 2008). This is further discussed in detail in the data analysis section of this chapter.

As with any research approach, BNIM also has its critics. Ross and Moore (2014) have stated that their concerns are around the method leading to disruption in metanarratives because of it privileging subjectivity over understanding social objectivity. Use of a Single Question Aimed at Introducing the Narrative (SQUIN), (discussed in detail later in this chapter) and sub-sessions as an interview technique, where individuals tell their story without interruption, has had critics argue that the 'Dialogic possibilities' may be lost in this process (Hollway \& Jefferson, 2000). Ross and Moore (2014) also argue that narratives can be captured in much more detail in a traditional interview approach. BNIM data analysis and use of a panel setting has also been scrutinised as Bornat (2008) claims that the use of a panel to interrogate and rework the told stories of individuals leads to biological narrative interpretive method to favour subconscious motivations over the meanings individuals attach to them. Bornat (2008) further states the subjectivity of individuals' told stories suffers from overreconstruction and over-scrutinising leading to a rise in ethical issues due to the democratic relationship being lost in the data analysis process.

Despite its critiques BNIM has been successfully used in a number of research studies with older people (Rosenthal, 2003; Vajda, 2007). It offers health and nursing research another resource from which to explore stories of health and or illness. This approach enables understanding of human experiences in the form of biographical narrations or life story telling. It transcends the barriers between individual self, society and the past, present and future (Jones, 2002). Storytelling and reliving memories, especially for older people, can be therapeutic. Using this method, I could offer the gift of listening and for the participants an ability to share their memories and lived experiences. Participants connected with their past while living in the present. It supports 
researchers to study and interpret psycho-social perspectives, historical and biographical dynamics of a persons' life story (Wengraf, 2008). It presented me with a platform to explore and explain in depth the social and historical positions of the individuals' lives.

\subsection{Methods of Sampling, Recruitment, Data Collection and Analysis}

\subsubsection{Sampling}

Sample size in BNIM are typically small. The ability of this method to generate adequate rich and meaningful data compensates for the small sample size (Braun \& Clark, 2006; Jones, 2002). I chose to have a maximum of 10 participants for this study with the aim to have participants of varying cultural backgrounds.

At the beginning of the study, I found it a challenge to recruit all 10 participants. This was due to my advertisement not targeting specific individuals, as I was sending information to residential facilities with the hope that information may then be passed onto prospective participants who may be interested in the study. I employed this method, as through my clinical experience I was aware that this group of participants were more likely to be found in residential or nursing care homes. Email addresses for care home facilities were accessible through the 'eldernet' website so I sent information sheets (Appendix 2) about the study by email to all local residential care home managers. I also approached my workplace geriatricians and provided them with information on the study. This first attempt yielded five prospective participants for the study.

I decided to use a snowball sampling technique to recruit further participants. Snowball sampling technique works on the bases of nomination (Sadler, Lee, Lim, \& Fullerton, 2010). It starts with the researcher having one or two recruits and asking them to nominate other individuals who may fit the criteria of the research study (Denscombe, 2010). The snowball sampling method produced only one other nomination. I approached this prospective participant only to be met by a refusal to take part in this study. 
I decided to continue on my quest of recruiting participants using a different approach. On the advice of a colleague I started looking through local newspapers for articles related to the celebration of hundredth birthdays. The local newspapers had a great source of information about these participants. News of them turning a hundred and its significance often appeared in the local papers. Most of the local papers provided names of residential facilities where the prospective participants currently resided. I called the named facility as listed by the newspaper and approached the facility manager or senior clinical staff about my study. They then took my request to the prospective participant. Once the participant agreed, the manager or senior clinical staff called me back. When I did not hear from them for at least a week, I followed up with another phone call to the facility contact person. Consequently, through the power of media, I was able to recruit the further five participants that I needed for the study.

Once the participants had agreed to take part in the study, I sought verbal consent and a phone contact for their family members. The involvement of family members at the time of conducting the interview was to provide emotional support to the participants. I also wanted to make sure that the next of kin for these individuals were well informed about the process.

Inclusion criteria was that participants could provide informed consent and take part in the interview and provide an account of their lived experiences. Participants who had hearing and speech impairment however could, through assistive devices, take part in the study and were included. Participants who had severe sensory and cognitive defects and could not recount their stories were excluded from the study.

\subsubsection{Ethical Considerations}

Ethical requirements in any research is concerned with ensuring participants' interests and rights are safeguarded through maintaining respect and participants' integrity throughout the research process. These requirements were met by ensuring confidentiality of participants was maintained at all times in this study. However, as a researcher I was also aware that due to the nature of my study being a biographical narrative, and rarity of the type of participants in my study, it may be difficult to conceal their identity in publicly available work. I have tried my best to promote anonymity of these participants' without distorting my data. However, I am very aware that they may be easily identified by friends, family and staff of the facilities where they reside. 
Interviewing, as a means of data collection in qualitative research, is viewed as a moral inquiry (Creswell, 2009; Kvale \& Brinkman, 2009; Kvale, 2007; Turner, 2010). It is important to ensure all steps and actions are taken to avoid marginalisation or disempowering study participants (Creswell, 2009). To promote this, ethical approval for this study was gained from Victoria University of Wellington Human Ethics Committee (Appendix 3). I provided the committee with online completed forms to seek for ethics approval on the Victoria University of Wellington Website. Other documents included with this application was the research proposal, information sheet (Appendix 2), participant consent form (Appendix 4) and a prompt sheet with interview questions and cues. (Appendix 5). Minor amendments requested by the ethics committee were completed and the application and associated forms were resubmitted.

I provided all participants and next of kin with an information sheet. The information sheet clearly outlined my details, reasons of conducting this research, benefits and risks of taking part in this research (Appendix 2).During my first contact and prior to completing the written informed consent form, I ensured that participants had all the information about the study. I also spent time with them to answer any questions they had regarding the interview and the study.

\subsubsection{Recruitment}

Many challenges have been noted by researchers in the recruitment and studying of centenarians: such as obtaining an adequate sample; difficulties with age validity; frailty; high mortality rate; and a variety of gatekeepers who limit access to them (Sachdev et al., 2013; Yang, Salvin, \& Sachdev, 2013). These hurdles are very similar to what I faced during the recruitment stage of this study.

My aim was to recruit 10 individuals aged a 100 years and over for the study. Age confirmation was through care home staff and by participants themselves. Eight participants lived in residential care homes and two lived in a semi supportive environment.

I offered the use of a hearing device for participants who had hearing impairments but could narrate their life stories. Participants who agreed to trial the hearing device found it to be a distraction and very early on in the interview process declined to use it. 
Participants were happy for me to repeat questions and speak loudly rather than to use an assistive device during the interview.

Staff at the residential care facilities were generally very prompt with the participant's replies about taking part in the study. Once I had received a positive reply from the facility, I made an initial phone call to the prospective participant who had agreed to take part in the study. I introduced myself and the purpose for my phone call and organised a time to meet. I also asked if I could, at this meeting, organise for the interview to take place. During this phone call I also brought up the topic of contacting their next of kin to make them aware of the study as well. Once verbal consent was gained from participants to allow me to contact the next of kin, I asked the participant for their name and contact details. The majority of next of kin were willing and agreeable for their centenarian family member to take part in the study. However, I did encounter one family member who refused access to their mum and did not provide permission for me to meet and ask her to consent for the study.

Sachdev et al. (2013) has documented the limited access that researchers are provided to these participants, generally from a variety of gatekeepers such as next of kin and facility staff. As mentioned above, I experienced this on one occasion when a participant in the facility was identified by the staff as being a suitable candidate for the study. They did however request for me to contact the next of kin prior to making any contact with the prospective participant. I therefore called the family member and provided information about purpose of my study and what it involved. I offered to send a written information sheet and also was willing to meet her to go over the study design with her. Despite this, the family member declined for her mum to take part in this study. Her reasons for this was that it was going to cause her mum added stress and distress to her during the interview process. The family member did not want to elaborate further as to her reason for thinking this way about her mum. I therefore did not pursue with this and respected her decision to deny me access to her family member.

\subsubsection{Data Collection}

According to Creswell (2007) data and data collection fall into four basic categories: "Observations, interviews, documents, and audio-visual materials" (p.129). The main source of data, when using the BNIM, is interviews (Wengraf, 2008). In this method, 
data is collected through face to face interviews in the participant's environment using unstructured open ended questions. This was so the interviewees could talk about their experiences and move to topics that were of significance to them (Denscombe, 2010). As a novice researcher I wanted to ensure that data collected through this method was rich and relevant to my study. I created an interview protocol to assist me with my data collection (Appendix 5). An interview protocol is not just a list of interview questions but also covers the procedural level and acts as a guide during the interviewing process for new qualitative researchers (Jacob \& Furgerson, 2012). This included written prompts for what I was to say before and at the conclusion of the interview. During the interview, I took some brief notes which were to assist me with further questions as the interview progressed about topics that I wanted the participants to further explore. I also took field notes in the form of audio-tape recordings of my reflections after the interviews had been completed with participants.

\subsubsection{Conducting the Interviews}

Narrating lived experiences of the participants through uninterrupted methods of interviews produced rich data. I facilitated this through ensuring minimal interruptions to the flow of information by using "Paralinguistic expressions of interest and attentiveness such as " $m h m$ " or during narrative interruptions through motivating incitements to continue narrating, such as "And then what happened?," through eye contact and other physical signs of attention" (Rosenthal, 2003, p.918)

The aim of this method of interviewing is to cause as little interruption as possible, I was however, repeatedly asked questions by the participants throughout the interview process. Some of this was due to them not being sure of what they should be disclosing to me. The other reasons being that participants would start to tell their story and in the middle of their sentence required reassurance that they had answered my questions and also that they felt that they had side tracked from the questions and required reorientation to the question as while they were talking they had forgotten what the actual question was in relation to the answers that they were providing to me. Rosenthal (1993) has stated this could be due to a number of reasons including and not limited to the misinterpretation of question asked by the interviewer and the interviewee's reaction to these opening questions and the narration may be dependent of their overall biographical constructions of their told life stories. 
In the BNIM of interviewing Rosenthal (2003) suggests the interview should be in phases as known as sub-sessions. According to Wengraf (2008) BNIM of interviewing is divided into three sessions. These sessions provide the interviewer with opportunities to revisit the participant to ask further questions. The interviews for this study loosely use the suggested technique as explained by Wengraf (2008). I decided to have only one sitting with the participant and use the same sitting to go through the different sub-sessions. I later followed this up with a phone call to the participants if I had any further questions for topics that I needed to revisit. The reason for this being that the participants were of a very vulnerable group. Their age and frail health status meant that I may not get to revisit them for multiple sessions and may lead to my interview being incomplete due to severe illness or even death of the participants. Due to this I have referred to the sub sessions as phases of the interview process.

The first phase of the interview starts with a "Single Question Aimed at Introducing the Narrative (SQUIN)" (Wengraf, 2008, p.7). SQUIN presented to participants of this study was: Can you tell me what does it feel like to turn a hundred and how has this lived experience changed or affected the way you see yourself and others?

The second phase of interviewing is to gain more insight and more stories and narrations around "Particular Incident Narrative (PIN) and away from theories, arguments or justifications" (Ramvi, 2015, p.25). Questions asked in this second phase of the interview were from notes taken during the main interview. This meant that I was not introducing any new topics at this stage and was only guiding and inviting the participants to provide deeper narration of their experiences (Rosenthal, 2003).

I included a third phase of questions in the interview on topics of interest to me for example, I included interview questions on cultural significance (being in New Zealand) and the impact of society and major events such as the two world wars had on their experiences of living to a hundred.

I was aware that questions around some of these issues, such as the World War One and Two could be traumatic for some individuals. To minimize such stressors, I ensured that questions asked about these events in their lives were posed in a subjunctive manner. Rosenthal (2003) states that if difficult areas of life are involved, then posing questions in a subjunctive manner is more beneficial; questions such as: "Perhaps you could go into a bit more of detail regarding your experience...?" or "Could I possibly ask you about the time when you... ?" (Rosenthal, 2003, p. 919). 
Interviews lasted for 45 to 90 minutes. I used an audio-tape recorder to record the interviews. This enabled me to revisit the interview several times and allowed me to transcribe the interview comprehensively looking for voice tones, and silences in some cases. Most of the participants were able to talk clearly and transcribing these recordings was not an issue. There was one interview with a participant, in the initial stages of the study, when the participant insisted on having the interview in the common area of the facility. This meant that the interview recording was not of very good quality as there was a lot of background noise. I was however able to transcribe this after listening to it carefully and repeatedly. Through this experience I learnt to request for the interview to be in a quieter area, participants respected this request and I was therefore able to avoid much of the background noise in later interviews.

While I initially started taking notes during the interview, I noted that this was promoting a barrier as participants would lose track of what they were saying and start concentrating on what I was writing. It was also becoming difficult for me to concentrate on what they were saying; I was left behind in the conversation as I tried to take notes. As I got more confident with the interviews, I noted that I could ask questions about events that needed further clarification without having to take notes. Using an audiorecorder as opposed to taking notes during the interview aided with reducing barriers and interruptions that would have prevented an effective flow of the interview.

\subsubsection{Data Analysis}

Biographical narrative interpretive method of data analysis is unique to all other qualitative data analysis techniques as it uses a panel for data analysis and interpretation. According to Wengraf (2008) use of a panel for data analysis and interpretation assists with reducing the effects of blind spots and limits one's own ignorance and subjectivity. It also assists with future blinding the interpretation of data as the panel only get to see and develop hypothesis on chunks of data that is presented to them one-by-one (Wengraf, 2008). There are 10 specific steps to data analysis with the use of the BNIM (Wengraf, 2001). It involves verbatim transcripts and interpretation of transcriptions and field notes twice in steps 1 and 2, to panel involvement in data analysis and interpretation in step 3 to step 5. Step 6 to 10 involves bringing the two (researcher and panel) interpretive tracks together for micro-analysis and interpretation (Wengraf, 2001; 2008). Researchers have stated that this method of data analysis is 
not only very complex and time consuming but possess the risk of over - interpretation and is also at risk of 'Distancing interviewee's from their own words' (Bornat, 2008, p.353).

I therefore used Colaizzi's (1978) method of data analysis (Appendix 6) and a thematic analysis approach as opposed to BNIM's preferred data analysis technique. Colaizzi's method of data analysis is fundamentally embedded in descriptive phenomenology approach. The analysis is carried out in a thematic field analysis format with the purpose being to re-construct biographical meaning of experiences in a chronological sequence of experience in which they occurred. Thematic field analysis is used to interpret meanings of their lives and experiences in a form and structure of the narrated life story (Rosenthal, 1993).

A transcriber completed the transcribing of the audiotaped interviews. The transcriber signed a confidentiality agreement form before I sent the audiotapes to her electronically (Appendix 7). Once the transcriptions were returned, I listened to the original interview audiotapes and checked the verbatim transcription against the audiorecording to ensure accuracy. My academic supervisor also had access to the verbatim transcriptions. This was to enable me to debrief and to discuss emerging themes. My professional background as a geriatric nurse also provided me with familiarity with the phenomena under study.

The initial step to data analysis was through listening and re-listening to the original interview audiotapes and reading and re-reading the participants' description of the phenomena. This was completed to obtain a sense and feeling of their individual accounts and experiences. This initial step of comprehensive data analysis also involved referring to my field notes and reflective audio-tape recordings. This phase enabled me to extract significant and meaningful participant statements relevant to the phenomena under study. I listed these individual's accounts of each phenomenon in a chronological order and then looked through the ten biographies for commonalities and patterns between narratives. I was able to formulate and discover meanings from these statements. I further organised these under clusters of themes and subthemes (Appendix 8) and checked these against the original transcriptions and audiotapes for validation with the participants' original stories. I examined the data vertically, in terms of participants' narratives, and from a life course and intergenerational perspective (Wojnar \& Swanson, 2007). 
I carried out participant confirmation or member checking of my findings by returning to the participants and asking them if the themes reflected their experiences as centenarians. There were five participants that I was not able to return to for member checking. This was due to the increased frailty, severe illness and the occurrences of death which did not permit me to undertake this stage of Colaizzi's method of data analysis for all participants.

\subsection{Quality of the Study}

The study of individual subjectivity in biographical and narrative inquiry and the lack of objective data in qualitative study makes it hard to measure validity of such studies (Nilsen, 2008). Multiple realities, subjective nature and views of respondents shape the study. The various standards used to ascertain quality and trustworthiness of this study were credibility, transferability, confirmability and reflexivity.

Credibility was achieved through my role as a nurse specialist in care of the older person, I have always had an interest in the ageing process specifically positive ageing. My interest in centenarians was heightened by an interview that I had conducted for a previous paper on Age and Ageing through Victoria University of Wellington. These experiences were so exhilarating that I wanted to understand more about centenarians and how it felt to be a hundred. Prior to this study, the majority of my contact with the older person has been in a hospital setting. One possible way to improve credibility of the study would have been to have the ability to use member checking for all participants in the study. Transferability in qualitative research was utilised to gauge the extent to which the study findings can be applied to other settings (Byrne, 2001). The study findings provided for a rich description of data with purposive sampling used to recruit participants. Confirmability was achieved through maintaining specific documentations throughout the study. These included a research journal, field notes and original data in the form of interview audiotapes, verbatim transcriptions and interpretations and analysis of data. Research report and summary of communication with participants were kept for future reference in a password protected computer. 


\subsubsection{Reflexivity}

Reflexivity relates to the impact of a researcher's understanding, personal views and values have on data collection and analysis (Carolan, 2003). It enables the researcher to acknowledge the roles and influence that he or she may have on the research project. Reflexivity provides a means of providing credibility to a research project as the researcher's self-reflection throughout the research enables an understanding of the impact that they have on the research (Carolan, 2003; Doyle, 2012). Through the process of reflexivity, I was able to better relate the phenomenon under investigation to a research methodology that was much more reflective of the participants' stories. Through this process, I was able to change from a descriptive phenomenological approach to a biographical narrative interpretive method of inquiry.

According to Chamberlayne et al. (2000) the telling of one's story can often uncover raw emotions and traumatic memories for the participant and therefore requires the researcher to be able to provide therapy and emotional support. The researcher should be able to guide the interview in a way to end at a position as to not leave the participant in a state of unwanted memories and burdensome feelings (Rosenthal, 2003). On the other hand, biographical and narrative interviews have also been known to have a therapeutic effect as retelling one's story can have positive physiological effects on the interviewee (Rosenthal, 2003) and this was my experience when undertaking this research. All participants expressed how much they enjoyed the session and invited me to come back if I had any further questions.

These are two very distinct but interwoven effects of interviewing about the lived experience that is emotional as well as therapeutic and satisfying to the interviewee and the interviewer. As a researcher, I ensured that I had made every effort to give power back to the participants to guide the narration as to what they felt they wanted to talk about in regards to their experiences and life story. Further questioning during the interview was limited to the stories that they had already narrated to me.

I also reflected on my practice as a novice researcher with my academic supervisor on a regular basis. 


\subsection{Summary}

In this chapter the objectives and proposition for this study were outlined. I have provided a rationale for the change of methodology and the methods used for data collection has been described. The process of recruitment, interviewing and data analysis has been explored. I have also discussed the quality and reflexivity of the study. The next chapter presents the findings, setting out the themes and sub-themes. 


\section{CHAPTER 4 - FINDINGS}

\subsection{Introduction}

In this chapter I present the study findings. Ten participants took part in this study with the age ranging from 100 to 106 years old. Participants consisted of three males and seven females. They were all of European background with six of the participants born in New Zealand and four born overseas. Table 1 provides a brief overview of the participant demographics. Pseudonyms have been used to ensure confidentiality of the participants.

\begin{tabular}{|l|l|l|l|l|}
\hline PARTICIPANTS & GENDER & $\begin{array}{l}\text { AGE AT TIME OF } \\
\text { INTERVIEW }\end{array}$ & CAREER & $\begin{array}{l}\text { MARTAL } \\
\text { STATUS }\end{array}$ \\
\hline Mira & Female & 100 & Shorthand typist & Married \\
\hline Bill & Male & 100 & Lawyer & Married \\
\hline Connie & Female & 100 & Accountant & Married \\
\hline Mike & Male & 100 & Engineer/Businessman & Married \\
\hline Helen & Female & 100 & Shorthand typist & Married \\
\hline Mary & Female & 100 & $\begin{array}{l}\text { Kindergarten teacher, } \\
\text { Office worker, } \\
\text { Businesswoman }\end{array}$ & Single \\
\hline Wini & Female & 100 & Nun & Single \\
\hline Alice & Female & 100 & Shorthand typist & Married \\
\hline Joy & Female & 106 & $\begin{array}{l}\text { Worked in her father's } \\
\text { general store }\end{array}$ & Married \\
\hline Kiryl & Male & 100 & $\begin{array}{l}\text { Policeman, Businessman } \\
\text { Married }\end{array}$ & (100) \\
\hline
\end{tabular}

\section{Table 1 Brief overview of participant demographics}

See appendix 9 for more comprehensive details of participant demographics. This is to provide additional information about each participant and their background including: gender; position in the family; marital status; their country of birth; and a brief account 
of their careers. I have also included the occupation of their parents to provide some insight into their socio-economic backgrounds.

The overarching theme was the nurturing that all participants experienced throughout their lives. A diagrammatic depiction of how the life stories of participants demonstrated a common pattern of their attitudes towards becoming a centenarian was developed as part of data analysis (Figure 1). Throughout this chapter I refer to these as themes see (Chapter 2 - research design).

Five main themes were revealed in the data. These were: becoming a centenarian; growing up in a privileged environment; opportunities in adult life; ageing and celebration of longevity, and generational events. Subthemes are depicted in the diagram to demonstrate participants' life journeys, and although their stories are individual accounts of their lives, there are commonalities throughout, particularly in regards to their childhood and upbringing. All participants verbalised having nurtured and well supported relationships with their parents and other family members. The diagram is used to demonstrate the link between their attitudes to life, as a centenarian "just another day" and how this attitude was a pattern throughout their lives, and (I suggest) may have contributed to their longevity.

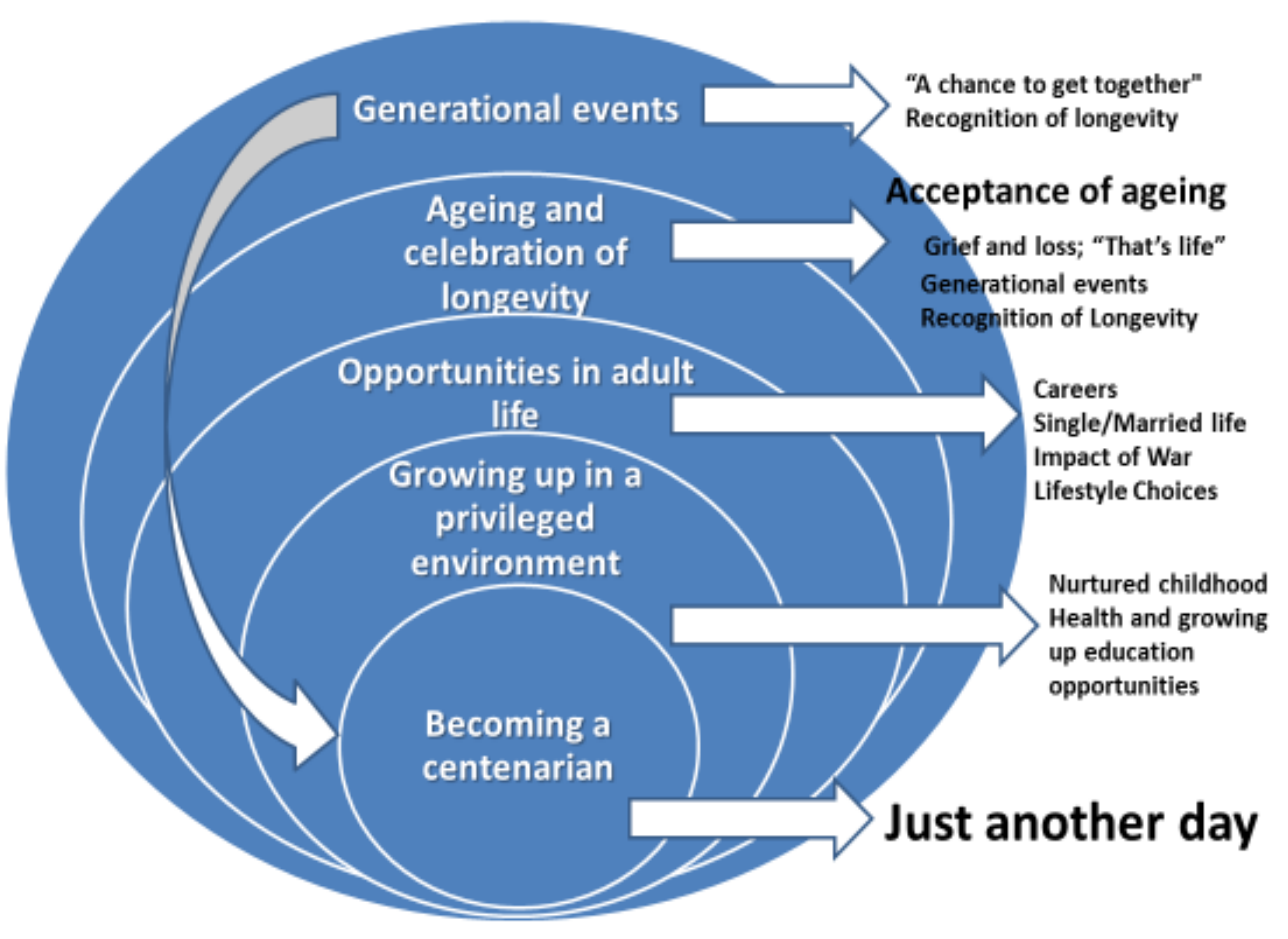

Figure 1: Diagrammatic depiction of the themes 


\subsection{Becoming a Centenarian}

\subsection{1 "Just another day..."}

The centenarians spoke nonchalantly about their experience of turning a hundred. Participants described this phenomenon as being "no different" to any other day and did not consider this milestone as an achievement or a significant life changing experience. They all shared the same views about extended longevity, some referring to it as "just another day":

Well it just seemed another day for me...No different. You know when you wake up and it's your birthday you don't feel any different do you? Well that's just the same when you get to 100. (Mira, 18,110-113).

Well the first thing that I was pleased that l'd got there and I appreciated all the congratulations but otherwise just another day. (Helen, 7-8).

Oh it didn't feel any different. No just thinking about the party and hoping it would be a success that sort of thing. (Joy, 39-40).

My experience of turning 100 well I don't know that I wouldn't call it an experience it's just like every day it comes along and there you are. Suddenly you realise you've turned 100 years old and that's it and each day after that is over 100. That's about all I can tell you I mean there was no flash of lightning or anything. Just like a normal day but I don't know what else I can tell you. (Alice, 11-15).

I don't think I had any great feeling of change. You anticipate it and you're pleased you achieved I suppose but other than that I don't think that I had any great sensations of change. (Mike, 30-32).

I see nothing spectacular in because l've achieved nothing special. All that happened was I didn't die. That's all... Well I can't say that I see anything 
special it's no different from being 99. If I had climbed Mt Everest or fallen over some cliff or done something spectacular fair enough but I haven't. I've just lived and I didn't want to live to be 100 I hoped to avoid it. (Mary, 126132).

Well I don't know, I think it's just another day of the week it's just about the same as any other day...I don't know about it doesn't worry me being 100 or what, it's a number as far as I'm concerned...it's no different really from being 99 or 90 or whatever, it's a number as far as I'm concerned... To me it's just another number you see so that I don't look on 100 as being something special. I look on that to be a number, I suppose we've got to admit you've lived a long time to get to 100. (Connie, 4-5, 8-9, 19-20, 444448).

Well I don't know that there is anything really special about it. It is really just another year but I suppose you're getting older and able to do less things. (Bill, 33-34).

Well I didn't think too much about it but I didn't feel too much different in myself you know in the way I was, what I was doing and all the rest of it. (Wini, 10-11).

Just an ordinary day, just an ordinary day... (Kiryl, 21).

This position, that turning hundred was "just another day" epitomised their attitude and responses to life and permeated the lives of these individuals. The narratives reflected a position and philosophy of resilience and an insouciant manner that had been a feature throughout their lives. They preferred to bypass and dismiss the topic of turning a hundred and were more interested in reminiscing about historical eras and narrate their life stories. 


\subsection{Growing Up in a Privileged Environment}

Privilege is defined by the online Merriam-Webster dictionary (n.d) as "a right or benefit that is given to some people and not to others". The use of the word 'privileged' for this study is to highlight the participants' comparatively favourable upbringing in terms of higher social and economic circumstance during their childhood. There were commonalities among participants in relation to their childhood and upbringing in that they all believed that they had been advantaged and lucky in many ways during their growing up and into adulthood. These were credited by the participants as reasons for character and personality development and ultimately extended longevity. Specific trends, such as having had nurturing parents and family, availability of healthy and fresh food produce and educational opportunities were commonly shared themes among all participants.

\subsubsection{Nurtured Childhood}

All participants verbalised that their parents, grandparents and older siblings had played a vital role in early developmental stages of their lives. Participants attributed their good health and extended longevity to being nurtured and protected by their families during their childhood years. The freedom to explore nature and learn through positive and practical advice from their family had assisted them to build their confidence and had contributed to their resilient attitude. They all reported having amicable relationships with their family members that were based on trust and care:

We did the things children do, my parents put us first definitely. They gave us a very happy childhood. (Mary, 99-100).

We had a very happy childhood. You know full of people who loved us and we loved them and no bickering. (Wini, 187-188).

I was very well looked after by my mother until I arrived into the world and I was very delicate. But you see this is what care does, looks after you...I 
was very very well looked after as a child because I was presumed to be delicate and so of course I had extraordinary care. (Mira, 116-118, 176177).

Although participants reported happy and generally free childhood experiences, they also reported a sense of strictness within a supportive environment. Their parents and other family members promoted and role modelled exemplary behaviour. This, they believed, had contributed to shaping their personalities through promoting discipline and respectful characteristics:

Well I think that we were brought up to know to do and behave ourselves and I think that has probably helped me through life I think, that I've been polite and understanding but I suppose you could say that should be normal. I think we're lucky our parents were fairly strict and we didn't run wild in that sense. (Mike, 371-374).

All participants had happy childhood memories that they cherished and they talked about these in great detail. Retelling these events provided them with an opportunity to indulge in the memories of their past. Each individual had retained aspects of some very specific moments of their lives. There was always a sense of satisfaction, pride and laughter in their voices as they absorbed themselves in retelling their stories:

I went on the edge of one of the swamps that were there they hadn't been drained and there was water in them just about that deep and the whole of the area where I was full of tiny frogs that had just developed their legs. Oh I can still remember so many you know. There must have been a hundred down there. Oh I could ride the old cart horse if I wanted. (Joy, 188-193).

Female participants specifically mentioned their mothers playing an important role in their lives in regards to nurturing. Some female participants also spoke of having strong bonds with their fathers. On the other hand, male participants referred to their parents in general as being loving and caring. Such close and trusting relationships enabled them to have positive role models in their lives and to become positive role models themselves. These nurturing relationships were reflected in the way the participants 
had attended to their own children and grandchildren. These nurturing relationships had also gone a full cycle whereby their adult children were now very involved in the care of their hundred-year-old mother or father/parent:

My family. Oh they've always been good to me... my daughter's very good to me. I mean she makes sure of things without being too obtrusive you know... so I know l'll be looked after. Don't forget your pillow Mum. (Connie, 266-271).

Oh wonderful. I mean I think my daughter has been marvellous to us and our two sons are very good. No I couldn't thank them all enough they've all been very good in every respect. (Mike, 381-383).

I'm very lucky I was with both my children they were very good to me. (Alice, 248).

\subsubsection{Health and Growing Up}

Participants' parents had all had a reasonably high income and they all mentioned having a backyard garden which provided a constant supply of fresh vegetables and fruit. Some participants talked about having cows and hens for milk and eggs and all had childhood experiences of home cooked meals that had been prepared by their parents. All participants attributed their extended longevity to good nutrition and having home cooked meals as a child:

So we must have been fed as well as children and later too because none of us were ever ill...I think my mother fed us very well but she wouldn't have known a ha'worth about nutrition...Very plain, always a roast on Sunday, usually fruit sponge pudding. Toast for breakfast, we had school lunches we took our own lunch to school, sandwiches and sometimes the man came from one of the local shops with pies and pasties, we'd be given sixpence to spend for lunch and you got a tuppenny pie and a tuppenny pastie and two penny cakes. (Mary, 107-111,324-326, 332-333). 
I've always you know my parents were very good on that because we lived on the dairy farm so I grew up with cream on my porridge... Oh I guess it does because when you're on a farm you have the best of everything and my mother was a great cook you know and when your meal was put in front of you you had to eat it...I was always you know I was brought up with good food and I think that was part of it. (Mira,28-30,39-41,187-188).

Nutrition been a major factor I think in my life. (Mike 415-416).

Well there were no vegetable shops as such in Karori in those days, every household had to grow their own vegetables or make some arrangement about getting some. And dad used to get up at six o'clock in the morning go out into the garden and work out there until eight, come in and he used to get his own breakfast and then go off to work just before nine. (Alice, 258263).

My mother had a big vegetable garden, she always grew plenty... I had lots of vegetables of all sorts and mum also kept fowls so dad built two quite big fowl houses and she had twenty or thirty chooks and so there was always plenty of eggs and stacks of milk. Not much cream because they took it off the milk which reduced its value at the factory so dad was keen on and he didn't like cream much either I think. But Mum grew, they grew a nice plum tree and she grew strawberries and grew loganberries on the vine and passionfruit so we had plenty of fruit and vegetables always. (Joy, 202, 219224).

Maize and wheat farming. It was very handy because you always had something to eat. (Bill, 199,205).

Apart from having nurturing families, the environment that they grew up in had a considerable influence over their health and wellbeing. For instance, Bill spoke about 
the differences between the environments of two different countries and the impact these environments on his health:

When I was in Africa, I was sick all the time with malaria or something... I was lucky I suppose to survive considering the amount of illness l've had. But once I came to New Zealand then l've been pretty good really. (Bill, 154160).

Joy on the other hand described the impact of her living environment within New Zealand on her health as a child. Her parents moved towns on the advice of health professionals so that they could provide Joy with a better chance of surviving her chest infections. Despite her father being well known and well established in his career, her parents moved towns and rebuilt their lives to ensure that their children could have better health outcomes:

My father was working for a tailor he was a very well-known man around the Hutt so my father, from what I can gather more or less managed the shop, the tailors shop and of course made suits and that...the doctor had told Dad that the Hutt was no good to me and my youngest sister who was just two years younger than me and that he would have to take me to a better climate so the next thing I can remember is that we were up in Paraparaumu. (Joy 43-45, 56-59).

Unfortunately, despite her parents' efforts to provide a more conducive environment for their children, Joy lost her younger sister to diphtheria shortly after they relocated to their new home.

\subsubsection{Education Opportunities}

All participants were supported and encouraged to take up education of some type by their parents and grandparents. Their privileged upbringing was again reflected by them having exceptional alternatives such as studying in a private school during an 
era when 'The Great Depression' ' was having a huge financial impact on many other families. A variety of choices and recommendations were available to participants in regards to choice of school and when to attend. For example, Bill was living in Africa on a farm with his parents:

Well my grandparents said I should go and get educated so I was brought over to New Zealand. (Bill, 209-210).

Whereas Alice's father chose her school on the basis of the health benefits that his daughter would receive by not having to travel far for her education. He opted to pay the fees of a private school so Alice could attend a school close to home:

I was always not unhealthy but I always had nasty colds in the winter and was a bit of a sickly child and dad thought well it was far better for me to go to the secondary school just round the corner instead of having to get on the bus and go to college in town. So I was one of a few that was able to go which was a private school and of course he had to pay fees but he was earning money then and he didn't mind. (Alice, 147-152).

All participants, except Joy, had continual schooling. Joy had interruptions due to recurrent chest infections, ill health and exposure to diphtheria:

The doctor had said that I wasn't to go to school for 12 months... Because I had exposure he reckoned I hadn't really got my strength back...I had a kind of in and out education. (Joy,105, 156, 178-179).

This 'in and out' of schooling did not, however, impede Joy from going on to have a career. After leaving school Joy worked with her father in merchandise where she gained skills in clerical and sales roles. Connie, Mike, Helen, Wini, Mary, Kyril were high academic achievers. They were able to complete their primary and secondary education and benefited with being able to secure good career opportunities as adults.

\footnotetext{
1 The great depression - Triggered by the crash of New York stock market in 1929. Its financial impact was felt in New Zealand in the 1930s with mass unemployment and wage cuts (Museum of New Zealand Te Papa Tongarewa, n.d).
} 


\subsection{Opportunities in Adult Life}

Similar to their childhood, all participants were provided with many opportunities as adults as evident in their told stories. They all worked and earned a living at some stage of their adult lives. Most of the females gave up work after being married while some continued to work while raising children and running a household. Participants were able to make lifestyle choices such as good eating habits, active lifestyle and maintaining active roles in their chosen community clubs and organisations. Females also displayed independence around choices such as having preferences around their marital status versus single life. Furthermore, all participants did not have any horrific memories or terrible impacts on their lives due to the Second World War².

\subsubsection{Careers}

All participants were in paid employment at some stage of their adult life. The female participants who married left paid employment and concentrated on domestic work and raising children. Two female participants namely Connie and Alice, continued to work after marriage. Connie's interest in figures naturally lead her to continue learning and eventually become an accountant. Connie's career was an example of a woman who worked in a highly regarded profession and one that was not common among females of this era. Connie's intelligence and privileged background contributed to her sound education and achievements:

When we were 11 there was an exam to see whether you could go on to secondary school and very few people went on to secondary school otherwise you left school at 14 and I was lucky I got one of the scholarships so I went on to secondary school and I went there till I was 16 and then I took another exam, I was going to be a nurse and I saw there was this exam to go into the civil service so I thought well I'll go. They used to give so many results and then I didn't think any more about it and then they called me up as they said all those who were in the very top ones they always took them so that was how I got into the civil service. I never set out to be in the civil service but passing this exam so I went to the Inland Revenue department

2 The Second World War (War War II) - A conflict that virtually involved every part of the world during the years of 1939 till 1945. New Zealand supported Britain and formed close bonds with the Americans as they defended the Pacific after its forces in Hawaii (Pearl Harbour) were attacked by the Japanese (Encyclopaedia Britannica, n.d). 
and all my working life I was in the Inland Revenue department...l'd always been interested in figures so I sort of studied that and I can't remember when it was but I did qualify as an accountant just you know studying... well I did get an accountancy degree. (Connie, 74-84,144-146, 404-405).

Alice on the other hand continued to work until according to her giving returning soldiers jobs was a priority over newly married females at her workplace:

Yes but not for long because the idea was they wanted to get rid of all this newly married women and give the returning men their jobs. (Alice, 140141).

Three of the seven female participants had careers as shorthand typists (Appendix 9Participants demographics). A career as a shorthand typist was considered one of high status and was a career that required passing exams and acquiring a high standard of skill. Helen and Alice talked about following their female family role models who had made the same career choices as shorthand typists:

I wanted to be a shorthand typist like my two older sisters and so I took exams and I had two years at Hutt Valley High school and then I went to a place called Banks College in Wellington on The Terrace. (Helen, 609-611).

It wasn't my idea of life and a cousin of mine told me that she was learning shorthand and typing to get a job in the government and I told my father that I wanted to study shorthand and typing and get a job in the government and he said yes I could. So I did that and that's what I did. (Alice, 79-82).

It was also an era where competition for jobs such as shorthand typist was not an issue and where a job in 'the Government' had status:

In those days you just walked into the government and said l've got my exam whatever it was junior or senior typing and so I would like a job and I got a job straightaway. That's how easy it was then. (Alice, 77-84). 
The depression impacted on career prospects for two of the participants. This meant, in both the case of Mary and Cyril, the necessity for changes in their career as job opportunities were reduced due to funding issues and new government legislations consecutively:

I did kindergarten training after I left school and I finished when we, the year that I finished it that December was when we came to New Zealand and there was a depression on and they withdrew the funding for the kindergartens so there weren't any jobs. And I went into a doctor's rooms and I stayed there for ten years. (Mary, 42-52).

Labour won the election and unions then became compulsory so the boss says to me l'm not going to pay you double the pay...so he sacked me and put his son in the office... and that was in 1936 so I was on the unemployed for a while during which time I did get some work. I was working for one of the merchandise firms delivering supplies of cheese, eggs, butter and all the rest of it round to the various shops by truck and then while one of our staff was either on the sick list or on leave or something or had leave or something anyway I was filling in. It was only a temporary job and then after that they put me onto, they had a section they wanted cleared and they gave me that job to clean that up. Then I had another job to do with for only a few days but the parents' home was being auctioned and the property and that and they wanted, there was a couple put in there to keep an eye out that the people didn't help themselves to bits and pieces that they hadn't paid for. So that was all the casual stuff I did there apart from the unemployment. (Cyril, 259-260, 264-278).

All male participants had secure well paid jobs and became established in their careers. They were the bread winners of their family. Bill and Mike were enlisted into the Second World War and were both in the air-force. Bill as an air-force ${ }^{3(* *)}$, and

${ }^{3}\left(^{\star \star *}\right)$ has been inserted to promote anonymity of information for the participant. 
Mike gained an engineering degree and worked for an engineering firm until he joined the air-force as a $\left.{ }^{4}{ }^{\star * *}\right)$ during the war. Bill studied to become a lawyer after the war and Mike went back to work for the same engineering firm that he worked for prior to the war. After the war, they both remained in their jobs until they retired. Cyril on the other hand did not take part in the war, however he felt the impact of the great depression on his career choices. After being dismissed from his office job, he joined the police force and remained there for 25 years. He ran his own trucking business after leaving the police force until he retired at the age of 65 .

\subsubsection{Single/Married Life}

Eight of the participants married. The two who remained single were female. They both had very different reasons for remaining single. Mary attributed her single life to the impact of the war:

I suppose you could make a sob story if you wanted to and say that from 24 to 31 I was in a town that had young medical students and every other man went away, all our potential husbands disappeared into the war zone and most of them didn't come back. So there were a whole lot of people left unmarried but I don't think I would have made a good wife anyway so it didn't matter. (Mary, 85-92).

She however did not have had any regrets around not being able to find a partner or get married or have children.

Wini on the other hand did not marry for religious reasons. She followed in her family's footsteps and became a nun as Wini's three aunties from her father's side were nuns:

When we finally professed, when we give our vows for life you get a ring and that's our wedding ring, we're married to the Lord as it were. (Wini, 471472).

\footnotetext{
$\left.{ }^{4}{ }^{* * *}\right)$ has been inserted to promote anonymity of information for the participant.
} 
Both single female participants displayed an air of independence about the choices they had made and were content with their decisions.

There were no cases of separation or divorce reported by those who had married. Alice was only one participant, who talked about a troubled marriage. Alice expressed that her husband had a drinking problem which she was not aware of until later on in their marriage. This had had an impact on her and she reported struggling with this period of her life:

In the early stages of our life we did very well it was only as Fred got into the drink and I didn't really realise how much into it he was because he was always late to go to bed at night, he never went before midnight he used to like reading and I didn't, I was always a fairly early go-to-bedder and of course I didn't realise that he was gradually getting into the drink and that's when our problems started. (Alice, 129-135).

\subsubsection{Impact of War}

Nine of the 10 centenarians were either born just before or after the start of the First War World ${ }^{5}$ in 1914. One participant was born five years before the First World War. Participants did not associate the war with many negative aspects of their lives. They all talked about the war and its impact as being a normal part of living during this period. There were no horrific stories or traumatic memories associated with the war for all those participants born and or bought up in New Zealand. Life carried on as usual and they adapted to the changes that occurred secondary to the war as part of daily living. None of the participants' parents were directly involved in the war and therefore were not separated from their children during this period.

The direct impact of the Second World War was experienced by one participant. Connie was born in England and remained there until she married. She remembered a time when her home was bombed during the war. Although she remembered the bombing incident in great detail, Connie did not talk about this as a horrific event. There

5 The First World War (World War 1)- started on 28 July 1914 and lasted until 11 November 1918. New Zealand supported Britain in this war (Museum of New Zealand Te Papa Tongarewa, n.d). 
were no sad or distressed emotions expressed when she related the story about the bombing event:

Yes, there was a flying bomb in the last year of the war I think not long before the end of the war and this flying bomb the bomb fell in the street behind us and our house was well it was damaged it wasn't, it was damaged beyond repair the stairs or anything you couldn't get up the stairs in fact I can always remember seeing the glass from the window hit the wall on the other side and there was lots of glass all over this wall. (Connie, 117-121).

Participants actually reported some happy memories related to the Second World War, particularly social gatherings and the influence of the Americans using New Zealand as a base during the Pacific War events. They saw this as an opportunity that provided for community gatherings and a chance to meet people from other countries, which would not have been a normal occurrence if the war had not been in progress:

Of course part way through the war the Americans arrived to take control of the islands so that the Japanese didn't invade us. So we had a good life, social as well because the Americans had plenty of money and they were always looking for girls to go to dances and things and you could always go, we would be told there was a dance on in the Majestic Cabaret and if we would go along to partner the Americans or the New Zealanders if there were New Zealanders but most of the social life was with the Americans there for a while because New Zealanders were all overseas. (Alice, 94102).

It was clear that participants had little exposure to the effects of the two wars and generally life carried on as normal during these periods. As adults, their focus was on bringing up their young families and choices about their own lifestyle.

\subsubsection{Lifestyle Choices}

All participants attributed their lifestyle choices as impacting on their longevity. This included having an active lifestyle, healthy nutrition, minimal alcohol intake, a sound 
routine and supported living. They had all had active lifestyles as adults. One participant who, until a few years ago, continued to volunteer and assist other people through his church. He started actively taking part in this volunteer work after the death of his wife. Keeping himself occupied in this way enabled him to feel content and positive. Another participant talked about doing charitable work such as knitting scarves and selling these to raise funds for Christchurch to assist with people affected by the earthquake. Apart from volunteer work participants spoke about keeping up with their physical activity in later live through small regular walks and talking part in activities such as music group that is organised by their residing facilities. This choice for some was a means of ensuring healthy living and for others it was a means of being able to socialise with other people with the same interests:

Well I suppose there was the general way of life that's allowed me to live on. I've been kept very fit, I used to walk a lot and I kept very fit and I think that's helped me live longer. (Bill 171-172).

After I left school I joined a tennis club and played tennis. I enjoyed tennis I didn't excel myself really but I enjoyed it and then in my old age I played bowls and I did very well at bowls and I enjoyed the bowling club, some of the days at the bowls was the happiest of my life because I was having exercise and meeting with other women and we were a lovely crowd. So that was a happy part of my life too... Yes, I suppose I was very, I wanted to be active and I wasn't content to be sitting at home reading a book or anything like that. I had to be doing things and if I didn't, wasn't doing things well mixing around a bit I was bored. (Alice, 379-390).

I have three good meals a day and I think that's you know all part of living to $100 . .$. l've never been what you would call a drinker you know with alcohol, the only l've ever had is perhaps a little drop of wine. (Mira, 2728, 189-190).

Good routine, good food of course and good routine. I'm a great person for routine I think that's important... Just the correct thing to do you know, get 
up at the same time and go to bed at the same time. Yes, I think that's very important well it was to me. (Helen, 196-200).

8 of the 10 participants resided in a residential care home and two of them lived in a supported environment where they were part of a group of tenants residing together. Participants particularly spoke about the assistance provided to them by residential facility staff, their neighbours and family members, and believed that having the support and care around them during later years of their lives had contributed to their longevity:

I honestly think living here (residential care facility) has helped me live to be 100 ... You know if anything went really wrong somebody would come to your aid. (Connie, 216, 220).

She (Cyril's next door neighbour) is like a daughter to me. She comes in here checks me over makes sure l've got everything, takes me to the doctor and takes me out. (Cyril, 42-44).

\subsection{Ageing and Celebration of Longevity}

The acceptance and changes related to ageing was very noticeable, not just by their physical appearance but also on how the participants thought and felt about themselves, others around them and their life journeys. Acknowledgement of ageing and 'laid-back-ness' may be a personality trait that they had had all their lives however it was a common theme among all the participants. The other prevalent theme among participants was enduring the passing of close family and special friends and the acceptance of grief and loss as part of living. They all verbalised that they were not troubled by the thought of dying. The centenarians however were delighted to talk about current events such as their birthday celebrations which provided them with a chance to meet family and friends. Participants also received several forms of recognition of their longevity, with the most common being the Queen's Letter ${ }^{6}$.

\footnotetext{
${ }^{6}$ Queen's Letter - refers to a formal birthday card that is sent on the celebration of an individual's $100^{\text {th }}$ birthday on behalf of Queen Elizabeth II.
} 


\subsubsection{Acceptance of Ageing}

All participants had accepted their physical changes as part of a normal ageing process. Even though they admitted to 'slowing down' they had adapted well to physical changes that had occurred due to ageing. Even with slowing of physical and mental capacities participants had found ways to overcome these and in doing so maintained their independence and positive views about life:

I try to have a little walk every afternoon around the corridors just to keep me moving it doesn't take more than a few minutes but it does keep me moving. (Alice, 206-207).

I do know I forget things especially when I'm wanting, you know I have to write them down now to make sure I remember what day of the week it is and everything else. (Connie, 17-19).

I'm quite happy being slow and sometimes I'm slow on purpose so that I don't fall or rush in where I shouldn't. (Helen, 12-13).

\subsubsection{Grief and Loss "That's life..."}

Participants did not display any distressing emotions when they talked about death and dying. They had experienced losses over the years where loved ones and special friends had died. Even though they all verbalised that they were saddened by the loss of their close family members and special friends, there were no tears or intense feelings around these experiences. There was a sense of acceptance of grief and loss and they had integrated grief and loss as part of living and managed these poignant moments through individual coping strategies that they had developed over the years:

Well most of my friends died long ago that's sad one after another has gone and that means l've got no old friends l've got new ones you know but they're not the same as people who have known you all your life but you just have to carry on. The longer you live other people don't live as long 
and therefore you've seen them all die which is sad... That's life. Nothing more I can say about that. (Connie, 140-144, 297).

All gone long ago that's the trouble with living too long you outlive your old long-time friends...sad. (Helen, 304-307).

Oh l've got a few but they've all died off now. I don't really have any friends.... Well they die off and you don't make new ones... I don't really make friends now. (Bill, 101-105, 109).

\subsubsection{Thoughts About Dying}

All participants articulated that they were not worried about dying and did not feel that this was something they thought about every day. They all accepted dying as a natural process of living and were satisfied and content with their past and life in general. Participants expressed and hoped to die peacefully in their sleep and were clear about not wanting to be resuscitated. They also acknowledged that they could not predict when they were going to die but accepted the fact that they were not going to live forever. They did not want their families to mourn, but wanted them to celebrate their lives:

I don't worry about it because I think well that's it. It's like a plant that dies that's how I look on myself as a plant it just dies... I don't feel like dying at the moment. Maybe I shall tomorrow or something. (Connie, 339-340, 484).

Oh it's going to happen sometime. I've got to face facts l'm not going to live forever, they ask you when you come into this place, into the care units but I was interested when I was in the hospital the other they asked me if your heart stops do you want to be got at to try and make it go again and I mean I said no. (Mike, 218-221). 
Oh the quicker the better and no one's to mourn. I didn't want to be 100 I wanted to die beforehand and I think I nearly did but anyhow I don't think it will be long now and I hope it won't because I've done all the things I want to do, there's nothing more...And I've told them no mourning. (Mary, 335344).

I'm quite happy to slide away in fact I have been for a long time because there's nothing left in life for me now. I can't do anything l'm not strong enough and no I'm quite happy to go in my sleep if that was the way I was chosen to go it would be lovely. I don't want to keep on hanging, what am I hanging on for? I'm not hanging on in this life for anything l've had my days that's what I feel but of course it's just something that you've got to accept. You go when your time's been chosen for you not when you choose it. (Alice, 283-289).

The position of the centenarians in relation to ageing was analogous and in many ways reflected their position in life. There was a sense of acceptance and satisfaction with life. It was clear that they were happy and content with living in the present. They did not have any concerns about the future, however they were happy to reminisce about their past and recall happy moments of their lives.

\subsection{Generational Events... "A chance to get together"}

Birthday celebrations of some form were arranged for the event of turning a hundred. The arrangements for the party was made by their family and friends. Some participants had been very involved in the party preparations while others had been happy with family taking a lead with planning the event. The birthday itself was not of great importance to the centenarians, what was most pleasing for all was the opportunity that it presented for them to have their family around them, reflecting the importance of family and the intergenerational significance of the chance to have their children, grandchildren as well as great grandchildren present at their special event: 
It was a chance to get together. We don't see family and friends who came who we don't see very often. It was a very happy occasion. I don't know that I can say much more about it. It became a bit of $a$, we had a lunch the owner of the golf club with about 70 odd people and we had great grandchildren who recited, sang a song in Welsh because they live on the Welsh border, great grandchildren. A little boy of nine and all in all it was a very happy occasion. (Mike, 19-25).

I've said family all gathered and made it a very happy occasion and that they were there from the babies and the little ones and I quite enjoyed having them. I did enjoy it you know I didn't think I would but I really did...of course they arranged a beautiful spread...quite good fun. (Mira, 18-21).

Helen on the other hand had a very different idea about how she wanted to mark her hundredth birthday. She had decided to dance on a table and her wish was granted by family and friends when she was propped up on a table to dance on the day of her birthday party. Helen laughed about this as she showed me photos of her dancing on a table with family and friends around her:

I just said when I'm 100 I'll dance on the table. I didn't think I was going to live to 100. And of course I did you see and there's the jersey... And then they jacked it up that l'd do it outside, that's the table outside... That's what I like, fun being happy. (Helen, 95-100).

Mary had used internet technology as a means of communication with family and friends from all over the world to celebrate her birthday. She was not very keen on a party but had a cake that was brought in by her niece. Staff at the home where she currently resided, shared this cake for afternoon tea with her fellow residents at her request:

I knew that a party or luncheon or anything else would just be beyond me and I went to someone else's 100th party, we have a lovely party and she slept in a corner. And I didn't want to do that so I was very pleased when I came up with what I called a Skypeathon... Well I decided that I would do 
that, I wouldn't have any visitors and so I circulated my relatives and friends and said no visitors, no emails, no presents and please observe this and don't, well of course they took no notice. They didn't visit, that's good but they did, I said I will be online on two hours on three different days and just Skype me and if you haven't got a computer ring me up. And so some sent emails but they did Skype and it was very good because the first two callers were people I worked with and they got together and I saw and heard them drink my health so that started it off. (Mary, 135-147).

\subsubsection{Recognition of Longevity}

All centenarians had some form of formal recognition of their extended longevity. These included letters from the Queen of England, the Prime Minster of New Zealand, local parliamentarians, and organisations and societies of which they were members. One of the centenarians was also provided with a medal of recognition from his previous workplace.

However, they were all quite sanguine about this recognition, as in Connie's case, where she pointed out that the Queen's letter was late and it just went onto the wall with the other cards that she had received from family and friends. She didn't have any sense that the letters represented care or appreciation or special recognition for living to a hundred, but that it was more of a formality:

Yes, it was a bit late but I think there was a postal strike at the time. But to be quite honest I couldn't care less about the Queen's letter... Oh it just went up on the wall with all the others. (Connie, 458-459, 464).

Others, such as Mary, were a little cynical and in her case annoyed at getting the letter as she had purposely not applied to receive it. Her feelings around this letter of recognition was that it was not from the Queen and that there was not much thought put into sending it to her personally. She even went on to say that she did not feel that this letter of 'recognition' had any vigorous checking process around it and believed that anyone could apply for the letter and they would be provided with it. She therefore did not feel that it was special in anyway. 
Well I was rather annoyed really because I purposely didn't apply for it which you have to do, somebody else must have done it, it's a very lovely photo of the Queen but it's only a Photostat and they don't even check it. The woman when I first rang up and asked about it what was involved I was told that you apply for it and she said that they have a lot of them and she said we could verify it but we don't. So you could have sent a letter in and say please send me a photograph of yourself and congratulations I'm 100 and they don't check it, they just send it... But you can't expect the Queen to there are hundreds and hundreds and thousands. (Mary, 14-23).

She did however have a particular official letter that she valued highly. This was sent to her from the Arthritis Society of New Zealand. She felt it was the most genuine out of all the official letters that she had received as it did not have an automated signature but was signed by the President of the Arthritis Society.

Generally, others were more excited about the Queen's letter than were the centenarians themselves:

Oh I got one on the wall this one, oh it was great excitement caused us much amusement. One lady she was very excited to see it. She said but how does the Queen know... She's got a nice little office in Wellington. (Joy, 322-326).

Wini noted a typing error on the letter in relation to her date of birth, although she was not bothered by this mistake, but she was puzzled about who had applied for the Queen's letter on her behalf:

Yes, it's actually sent out from somewhere in New Zealand...They had 14th of March on it. I think somebody in the office saw 1914 and they put 14th of March that's all I can understand...Somebody else did we didn't. I didn't apply for it. (Wini, 317-328). 
Mike was appreciative of receiving the official letters of recognition, but he was however, like the others, curious about the process that the Queen's letter went through, in particular about who sends it, how they knew about the birthday and where in New Zealand it came from:

I was puzzled as to how the record goes and where the records go I got one from the Prime Minister and from the Governor-General and from the Queen and all of them. I don't know l'd be more interested just to know how they find out you might say because that puzzles me because I don't think any of our family would have made a point of telling anybody. (Mike, 34-39).

Bill was curious about the process yet very proud that he had received $\mathrm{a}^{7}\left(^{* * *}\right)$ badge. According to him, he was the only one in New Zealand to receive this award making it extra special. He wears this on his chest very proudly as he sits to talk to me:

Yes, I used to be in the $\left(^{* * *}\right)$ but I don't know how they found out about it

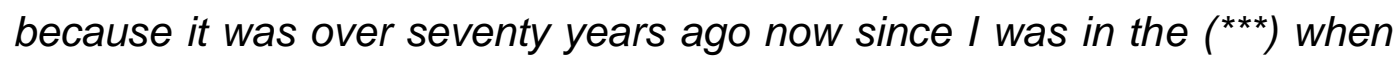
they found me and they gave me the badge. It's the only one in New Zealand they said. Yep... Well it is. It's a very special one really but then I'm the only 100-year-old person who had $\left.{ }^{* * *}\right)$. (Bill, 15-17, 19-20).

Similar to the others, Alice was appreciative but was not overly excited about receiving the letters:

Yes, I got one from the Prime Minister, one from Mr Dunne, one from the local man, I think that was all which was very nice. Routine I think, mind you, you have to advise somebody or other that it's coming up... Yes well I suppose everybody that turns 100 gets one if you apply for it, it's not as though it's automatic you have to apply. (Alice, 251-256).

Even though, to an ordinary person, these may be prestigious awards of recognition, the majority of the centenarians did not think of these accolades of distinction as significant. Most of them were of the opinion that it was part of a routine that

${ }^{7}\left(^{\star * *}\right)$ has been inserted to promote anonymity of information for the participant. 
governments and organisations go through to recognise extended longevity. They did however appreciate the gesture and were happy to share these moments, in the form of photos, cards and badges, with me during the interview period.

\subsection{Conclusion}

The experience of living to a hundred years of age was considered an ordinary event by the participants in this study. There were common patterns throughout the life stories related by the centenarians. As children, they were surrounded by family members who nurtured and loved them. They believed they had experienced a privileged lifestyle even though they had grown up through two world wars and other worldwide financial crises. Throughout their life journey, the centenarians had always been surrounded by supportive families and friends and this provided them with a strong foundation in terms of health and wellbeing as children. As adults, they continued to have opportunities which enabled them to make independent choices in their careers and lifestyles. This was reflected in their positive attitudes about the life decisions they made as individuals. They all demonstrated an air of independence, optimism, easy-going attitude and satisfaction about their life overall. 


\section{CHAPTER 5 - DISCUSSION}

\subsection{Introduction}

In this chapter the findings of the study are discussed in relation to current literature. I explore the key themes with reference to research, personal experience, current practice and policy. Limitations of the study and its implication for current practice are also presented. I also propose how the findings of this study contribute to the current body of research in this area. Referring to becoming a hundred as, 'just another day' and 'acceptance of ageing' reflected the attitude the centenarians had towards life and appeared to be a pattern threaded throughout their lives that may have contributed to their longevity, along with lives that were 'full' in terms of good health and companionship.

\subsection{Discussion of Findings}

\subsubsection{Childhood and Nurturing}

It is well known that adequate resources, good nutrition and a conducive environment in childhood provides for enhancement of longevity (Huang \& Elo, 2009; Schwartz et al., 1995; Smith, Mineau, Garobotti, \& Kerber, 2009). All centenarians mentioned having access to good nutrition, home cooked meals and availability of fresh produce during their childhood years. They all continued with good eating habits throughout their adult and later lives.

A number of factors such as parents and other family members and the environment have a critical role in the early developmental stages of a child's life (Schwartz et al., 1995; Smith et al., 2009). The ability to provide care and yet have boundaries which are positively reinforced enables a child to build strong characteristics and positive personality traits (Schwartz et al., 1995). All participants acknowledged and appreciated the positive role modelling their parents, grandparents and siblings had in their earlier lives and how this has had a constructive impact on their own personality development. Erikson's (1950), theory on psychosocial stages of development emphasise the role of society and culture on individual developments. The first five 
positive stages of childhood psychosocial development that is basic trust, autonomy, initiative, competency and identity are evident in these study participants. I have only discussed and focused on positive stages of Erikson's (1950) theory, as I did not see any evidence of negative stages of development in these participants' behaviours or in their told stories. Centenarians' nurturing childhood and its constructive effects on their later lives is one of the dominating themes and is prevalent throughout their told stories. They all came from privileged and stable socio-economic backgrounds. During their childhood the centenarians' were surrounded by parents and other family members who loved and nurtured them. This was evident in the way they talked about their parents, grandparents and siblings. Their positive outlook in life, pleasant personality traits and resilient characteristics can be traced back in their told stories about the care and nurturing they received during infancy and childhood years.

There were no specific examples of their infancy years in the stories they related but all centenarians mentioned the nurturing they received during their childhood years that was in keeping with the formation of a trusting bond between the two (infant and carer) as proposed by Erikson (1950). Trust was also evident as they all talked about coming from a close-knit family who looked out for each other and supported each other. Early learning of caring and nurturing for others gave them the ability to build the confidence and independence needed for their role as parents and carers of the next generation in their adult life.

Research has strongly linked growing up on a farm and having both parents as factors that decrease the chances of childhood mortality (Gagnon \& Bohnert, 2012; Preston et al., 1998). This can be linked to this study as the majority of the participants grew up on a farm and all participants had both parents present in their lives throughout their childhood years. Preston et al. (1998) also stated that being born in an advantaged socio-economic background provides the ground work for this advantage to continue throughout one's lifetime. This was also reflected in the study participants as all of them stated that they came from advantaged socio-economic backgrounds and they continued to have this advantage throughout their lifetime.

Erikson's (1950) second positive stage of the psychosocial development relates to attaining autonomy. Autonomy is described by Erikson as parents encouraging children to explore their limits and abilities in a supported environment where failure is not criticised and gaining a sense of independence is promoted, praised and were nurtured by their parents, grandparents and elder siblings (Svetina, 2014). There was 
evidence in the participant's stories of gaining autonomy and independence that was instilled in them during their childhood years. The independence and freedom of choice experienced by the participants provides some evidence that these have a lifelong effect that promote resilience (Cesarone, 1999; Miller-Lewis, Searle, Sawyer, Bughurst, \& Hedley, 2013).

Erikson's (1950) third and fourth stages of positive development; initiative and industry, refers to children learning to make decisions and feeling a sense of initiative. All participants had opportunities to learn and interact with other children through being provided opportunities to take up some form of formal education. Higher educational achievement and good-quality employment often improve health outcomes $(\mathrm{MH}$, 2015). The optimistic characteristics and positive outlook that they displayed in later life can be credited to their constructive learning and educational support during the early years of their lives.

Erikson's (1950) fifth stage of positive psychological development; identity, is described by Erikson as a stage where children are growing up to find their own place in society. The constructive and supportive environment that they grew up in as children was the foundation of this later positive stage. Identity in Erikson's theory also deals with finding the productive meaning of life. In the centenarian's stories they had all completed some form of formal education and all were in paid employment during some stage of their adult lives.

The accomplishment of intimacy and generativity of Erikson's (1982) theory for the centenarians interviewed was evident as they all talked about their established relationships with their parents, grandparents, siblings, partners, children and friends. Those who were not married also reached these stages as they also spoke about the significance of family and lifelong friendships with others. The centenarians also spoke about the support that they continued to get from these relationships in their later lives. The successful establishment and maintenance of such positive connections is a strong indication of these centenarians' progression through Erikson's positive stages of psycho-social development. This advancement promoted an ease of transition into Erickson's (1982) eighth and final stage of psycho-social development called egointegrity. Development of ego-integrity leads to virtue of wisdom in older age and provides a sense of accomplishment. Erikson has defined this as an individual coming to an acceptance his or her life and is satisfied with his or her past in all its triumphs and failures. Positive personality characteristics leads the individual to a stage of 
wisdom whereby they are able to look back at life events with a feeling of satisfaction, peace and gratitude. At this stage the individual reaches an acceptance of his or her life and is satisfied with their life journeys. Conversely, the development of negative personality characteristics through life events or obstruction by society can lead to the eight stage of disgust and despair and general dissatisfaction with life accompanied by a fear of death (Erikson, 1982). All of the centenarian participants had attained some form of ego integrity. There was also a noticeable separation of body and mind as centenarians talked about their physical and functional decline but however stated that their minds and mental awareness was still active and intact.

Another central finding of this study was that of the participants' carefree attitudes towards their experiences of turning and living to a hundred. Becoming a centenarian was seen as an ordinary event that held no real meaning or importance. For them being able to reminisce about their past and tell their life stories, especially about their childhood memories, was more significant. Erickson's (1968) term 'ego integrity' was a dominant feature in all participants. Participants looked back at their life with a sense of contentment, comradeship and wisdom with no regrets. In his book The Life Cycle Complete, Erikson (1982) summarised wisdom as the final stage of maturity and describes this as a kind of 'Informed and detached concern with life itself in the face of death itself' (p.61). Participants felt proud of their accomplishments and had a noticeable sense of integrity. Successfully completing this phase means looking back with few regrets and a general feeling of satisfaction. This was evident in all participants for this study.

Critics have highlighted that the Erikson's stages of psycho-social development do not fully account for racial, gender or ethnic issues as his theory is based on examination and research on developmental behaviour in white individuals in the 1960s (VogelScibilia et al., 2009). If critics are correct in their argument about its sensitivity to the white population, it may therefore explain the close association and reflectivity of his theories to my study participants as they were all of European decent.

\subsubsection{Stoicism, Resilience, Acceptance and Gender Bias}

The majority of the participants in the study were females and it is well established that females live longer than males (Eskes \& Haane, 2007; GHO, 2016; Vina \& Borras, 2010). Despite this advantage, research states that male centenarians tend have 
better cognitive and functional abilities and also have a greater compression of morbidity to later life when compared to female centenarians (Evert et al., 2003; Perls \& Terry, 2003).

Stoicism was seen in all participants in regards to their indifferent views on life as they spoke about negative and positive life events. This was evident when they all talked about the experience of turning a hundred as "...just another day..." as well as talking about their life struggles, grief and loss as “...that's just life...” Resilience and their acceptance of life was notable throughout their told stories, such as living to a hundred (Svetina, 2014) and recovering from illness, financial struggles, loss of physical functions and death of family and close friends. Yet, they continued to enjoy special moments and simple pleasures of life such as visits from their grandchildren, great grandchildren and their hundredth birthday celebration.

\subsubsection{Activity and Healthy Lifestyle}

The centenarians also stated that they had all been keeping themselves active as much as they could throughout their life. These included walking, cycling to playing golf and bowling in later life. Some of them also reported having an up-to-date interest in the current affairs of the country and voting in elections. The activity theory of ageing (Havighurst \& Albrecht, 1953; Schroots, 1996), encourages participation of older people in voluntary activity and other forms of social interaction. This theory states that the constant social interaction and physical activity will provide a sense of positive selfawareness and self-satisfaction. This was evident for all participants in this study.

\subsubsection{Tornstam's Theory of Gerotranscendence}

There was a sense of satisfaction with life that was very evident during the interviews with these participants. This stage is comparable to Tornstam's (1989) theory of gerotranscendence. There are three levels to the theory of gerotranscendence; the cosmic level, the self and the social and individual relations (Wadensten \& Carlsson, 2001). Tornstam (1989) further states that it is important to understand that not all individual will accomplish all level of this theory. All centenarians who took part in this study displayed evidence of gerotranscendence and that they had in some sense achieved some of these levels. 
The cosmic level of transcendence (Read et al., 2014; Tornstam, 1989) was noted in some form and at some level in all of the centenarians who participated in this study. The cosmic level of transcendence allows that individuals to have a universal view of life. Individuals do not find pleasure in materialistic items but delight in simple things such as watching nature or listening to music (Tornstam, 1989).

In keeping with Tornstam (1989) the centenarians in this study lived in the present and did not worry about the future nor the past. They were able to disconnect from the stressors of life and live in the moment. There was also a decreased fear of death and dying as they did not feel that it was a topic to stress or lose sleep over. When asked what their feelings were around death and dying, participants stated that they accepted this as part of living. Increasing significance of small everyday experiences such as nature and gardening can be interpreted as transcending between self and universe (Tornstam, 1989). It can however be argued that this could be interpreted as the older person using gardening to fill their idle time and lives. Also reflecting on the past can be seen by some as a natural thing to do as older people do not have anything else to do with their time (Wadensten \& Carlsson, 2001). However, the joy and excitement that was noted on these centenarians as they spoke about the past was seen as a positive reflection on life. While it could also be regarded as a social breakdown syndrome (Gruenberg et al., 1966) or social isolation and negative disengagement (Cumming \& Henry, 1961), it can be argued that the presence of a high degree of life satisfaction and absence of neurotic symptoms suggested that these participants had reached a cosmic level of self-development. The display of positive behaviours, active choices around social engagement and meta-prospective in life is well reflected by the gerotranscendence theory of ageing in these participants.

Tornstam's (1989) gerotranscendence level of the self is seen as self-confrontation, ego-integrity and rediscovery of the child within. All centenarians expressed great pleasure and enjoyment when they spoke about their childhood. Older people have better understanding of the other phases of their lives when they frequently return and reflect on their childhood memories (Wadensten, 2005). The centenarians talked about their childhood in great detail. Furthermore, accepting the aged body as normal progression of the ageing process, also known as body transcendence (Tornstam, 1989), was a feature of the centenarians. These centenarians had dealt with a number of major challenges and losses in lives such as Second World War, the great 
depression, the death of special friends and family members and decline in physical functions due to ageing.

Emotional distress, despair and depression due to past traumatic events, social isolation and functional decline in older people is well known and documented in literature (Davenhill, 2007; Dulin et al, 2011). When coping mechanisms are not in play the risk of emotional distress, depression and ultimately increased mortality is higher (Davenhill, 2007). However, it was notable that all of the centenarians in this study talked about past events with a sense of acceptance and recognised this as being part of living. These oldest of the old have a remarkable sense of satisfaction and acceptance of events (Hutnik et al., 2012) and these centenarians had all developed coping mechanisms that enabled them to continue to overcome stressor of life and therefore decreased their chances of mortality. Carstensen's socio-economic theory (1995) calls this positive bias which states that older adults reframe negative events in positive terms. This process promotes emotional regulation and provides for a peaceful passage through life (Carstensen cited in Hutnick et al., 2012).

The final level of Tornstam's (1989) theory refers to social and individual relations. It enables an individual to have a positive shift in thinking about life, change of views and meanings of social relationships to family and society. One example of a shift in meanings is around relationship with others. The centenarians had, over the years, become more selective about engaging with others. They preferred relationships with few people that held deeper meaning rather than having and developing new superficial relationships with others around them. There was also increased affiliation with future generations and their close family members. Another example of this was when centenarians spoke about spending time by themselves. This can be seen by many as isolating and passively withdrawing themselves from others. It can be viewed as a negative impact of ageing and put down to the older person not having sufficient energy to meet new people or are discontent with life (Wadensten \& Carlsson, 2001). On the contrary, centenarians in this study enjoyed being in their own company adding to the theory of 'positive solitude'. This is not because they lacked possibilities but more about the choices they made around the importance of social relationships in their later years of life (Tornstam, 1997). Turning to religion and their associations with religious organisation as a means to cope with loneliness after the death of their partner is well documented in research (Lopata, as cited in Thomas \& Eisenhandler, 1994). This was 
seen in one participant who turned to his church and volunteered for them after the death of his wife.

Furthermore, 'emancipated innocence' (Tornstam, 2005) was evident in the centenarians as they were able to break away from social role expectations and conventions. The centenarians had less care about how other people and society perceive them (Tornstam, 1997). One participant also spoke about blurring boundaries between wise and unwise and stated that she now refrained from giving 'good' advice and withholding judgement as she had increased tolerance and was much more broadminded. There was also modern asceticism evident in these centenarians as they showed little interest in materialistic things such as the manner in which they talked about received the Queen's letter (Wadensten \& Carlsson, 2001).

8 of the 10 participants lived in a residential facility. Literature from various studies suggest that the survival rate of individuals living in a residential facility is lower than that compared with the general population (Rothera, Jones, Harwood, Avery, \& Waite 2002; Wallace \& Prevost, 2006; Wilson, 1997). On the other hand, (Willcox et al., 2008) found that high quality long term care is linked to living beyond the age of 100 and attaining the status of supercentenarian. For all participants, relocation and transition to either a residential facility or a semi supported environment had had a positive impact on them. According to Wilson (1997) there are three transitional phases that the older person goes through when relocating to nursing home life, the overwhelming phase, the adjustment phase and positive adjustment and acceptance. The first two phases occur in the first few months of relocation. The positive adjustment and acceptance phase may take up to a year (Wilson, 1997). All centenarians living in care facilities had been residing in their respective residential facilities for longer than a year. This may explain the acceptance and comfortability that they displayed with their living environment. However, I suggest that, as their admission to these facilities was voluntary; a decision that they had made independently explains their easy acceptance of the transition. Some participants credited their extended longevity to their decision to stay in a residential care facility. They believe that the stress free environment and the care they receive from the staff had enabled them to live longer.

According to Lupien and Wan (2004), high education, high income and better physical health has been linked to higher cognitive function and successful ageing and there is a likely probability that successful agers are successful individuals throughout their entire lives (Lupien \& Wan, 2004). This can be seen in this study as all individuals 
came from good economic backgrounds and some of them have been very high academic achievers and continued to have high cognitive functions at an extreme age. Successful ageing is determined by having an emphasis on social interaction, life satisfaction and well-being (Crosnoe \& Elder Jr, 2002). Social interaction, although limited in the study participants, was one that held deeper meaning for them and as individuals age they tend to change their social relationships and generally have fewer social ties, however these ties often have more deep meaning to them (Helmuth, 2003).

\subsection{Study Limitations}

All participants were of European descent and therefore the effects of different cultures and ethnicity on extended longevity was not explored in this study. This may be accounted for due to Māori and Pacific islanders having a shorter life span (Dulin et al., 2011; $\mathrm{MH}, 2014 ; \mathrm{MH}, 2015)$. The study was limited to ten participants therefore knowledge generated from this study provides a limited view of lived experience of being a hundred years and over. There is scope to explore this topic further with a larger number of participants. Also participants were all in good health and the majority only required minimal assistance for their activities of daily living. This leads to a sample that is healthier and therefore stories may be told in a more positive light. Lupien and Lecours as cited in (Lupien \& Wan, 2004) found that aged individuals who more readily volunteer to participate in studies are generally more educated, in better physical health and have a higher income. These three components have also been very closely linked to the concept of successful ageing (Lupien \& Wan, 2004). It could also explain the positive stories and personality traits noted in this sample. Skewing of sample, also known as selection bias, is well known in the study of the oldest of old as it is easier to recruit healthier participants in this age range (Willcox et al., 2008).

\subsection{Personal Reflection}

I set upon this journey as a novice researcher with what I thought was a simple question with minimum prior knowledge and no prior personal experience of living to a hundred. I had very limited experience and exposure of dealing with the oldest of old and found it difficult to research and explore this topic. The whole experience has been 
both enlightening and enriching. Through this process, I have had tremendous growth in my knowledge and understanding about the research process, of positive ageing and especially in the context of extended longevity.

\subsection{Implication on Practice / Education}

Theories of ageing such as Erikson's (1982) ego-integrity and Tornstam's (1989) theory of gerotranscendence are important to develop understanding about older people especially for staff working in residential care facilities as they can provide the carer further insights into positive ageing. This will also enable guidelines and policies to be developed for practical use in the care of the oldest of old. Open discussion with older people about these theories, by incorporating this into the facility activities programmes may also enable them to identify this and provide a more positive view and a new perspective of ageing. It is hoped that this study will also enable staff of care facilities to support and individualise $100^{\text {th }}$ birthday celebrations to meet individual needs and wishes. It is also acknowledged that residential care facility staff play a pivotal role in supporting and providing care to these individuals. Therefore, investing in ongoing education and awareness programs for residential care workers is highly recommended.

\subsection{Conclusion}

This study has provided further insights into longevity and through the narratives of the centenarians has demonstrated the value of the theoretical positions of both Erikson and Tornstam. The research has demonstrated how centenarians may be notably content and happy with their life journeys, appreciative of their good health, supportive family members and residential facility staff who looked after them on a daily basis. The ability to obtain a higher sense of being and acceptance of ageing with a positive outlook on the past, present and future events is not a coincidence in these centenarians. The resilience and positive outlook in life can be credited to a childhood that was filled with parents, grandparents and siblings caring and nurturing for them. They did not experience poverty as they all grew up in a stable socio-economic status and all had a happy and normal family life. The lack of major illness and disabilities has also contributed to these centenarians' experience of a good quality of life. Stability 
in terms of their family and environment meant that they were able to deal with events such as death of loved once with ease. Positive adaptability to circumstances also came from their positive upbringing and stable lifestyles. The centenarians' family members especially their parents, grandparents, siblings and now their own children play a significant role around providing social support and emotional security. The centenarians in this study credited their physical and emotional wellbeing to the social support that was provided to them by their close family members, good nutrition and active lifestyle. This provided them with a sense of belonging and emotional security which they experienced throughout their lives. 


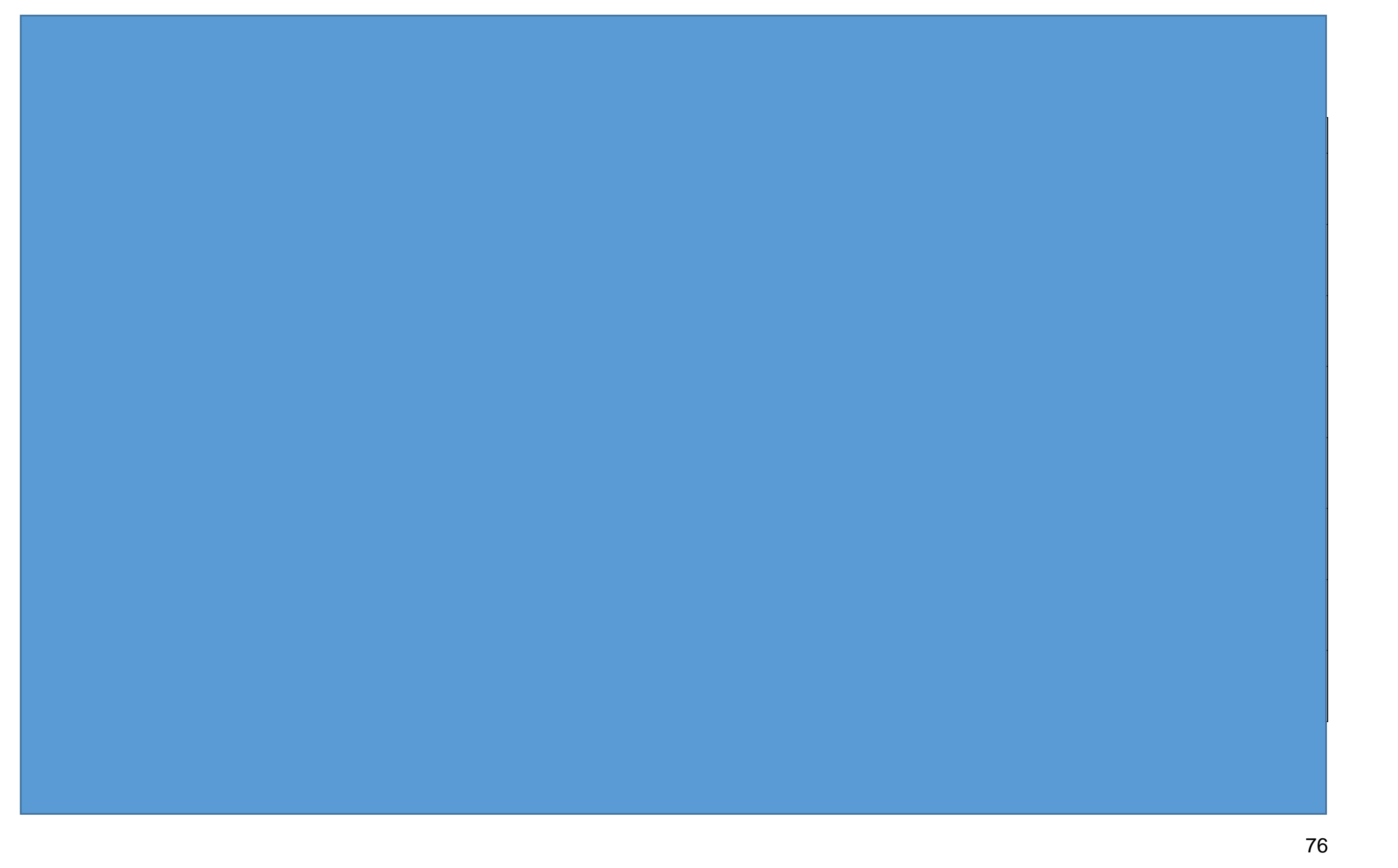




\section{APPENDIX 2: Participants Information Sheet}

TE WHARE WĀNANGA O TE ŪPOKO O TE IKA A MĀUI

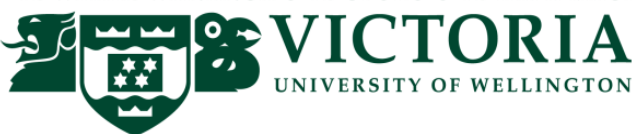

\section{INFORMATION SHEET}

\section{Looking at Lived Experiences of Being a Hundred Years and Over}

My name is Ashwina Naiker and I am currently studying for a Masters in Nursing Degree at Victoria University of Wellington. I work as a Nurse Educator at Older Persons and Rehabilitation Services at Hutt Valley District Health Board. My supervisor for this paper is Dr. Kay de Vries. (Head of School) at the Graduate School of Nursing, Midwifery and Health (GSNMH) at Victoria University of Wellington.

\section{Invitation}

You are being invited to take part in this research and talk about your experience of being a hundred years or over. Accepting this invitation would mean providing approximately two or more hours of your time to participate in interviews.

\section{Why is the research being done?}

The purpose of this research is to explore and identify the essence of lived experiences and meanings of extended longevity as perceived by centenarians and super centenarian.

\section{Benefits and risks of taking part}

Taking part in this research is voluntary. However, if you do decide to provide your contribution to this study, you will be asked to sign a consent form to show that you agree to take part. I do recognise that sometimes retelling your story can be stressful and may bring up unwanted memories. If it is found that reliving the experience is causing you distress, you are free to stop the interview at any time. You are also free to withdraw from this research without providing a reason up to two weeks after the interview.

I cannot promise that this project may assist you directly but the information provided by you will contribute towards research currently available on lived experiences of being 
a centenarian. This will also assist service providers such as primary and secondary care and residential facilities with further insight and understanding of centenarians. Further to this, it may have a therapeutic benefit for you as you get to relive your experiences and share your stories of being a centenarian.

\section{The interview (what will I have to do?)}

Upon agreeing to take part and providing a signed consent form, you will be asked to participate in an audio-taped interview. The interview will be carried out at the site of your choice and a time and date for this will be negotiated with you. You will be offered a follow up interview so that you have the opportunity to review a copy of the interview transcript.

\section{The results}

All information collected about you will be treated with respect and confidentiality will be maintained at all times. The results will be used in completing my thesis study and submitted for publication in journal articles and presented at conferences. A summary of the study results can be sent to you if you chose.

\section{Data storage and destruction}

All electronic data will be stored in a password protected computer. Hardcopies of interviews and transcribed audio-taped material will be stored in a secure place during the research phase and thereafter destroyed once the study has been completed.

\section{Research Rights}

Ethics approval has been granted for this study by the Human Ethics Committee at Victoria University of Wellington (Reference Number 20994). If you would like further advice as to your rights as a participant, you can approach the Health and Disability Consumer advocate by phoning: 0800555050.

\section{Contact Details:}




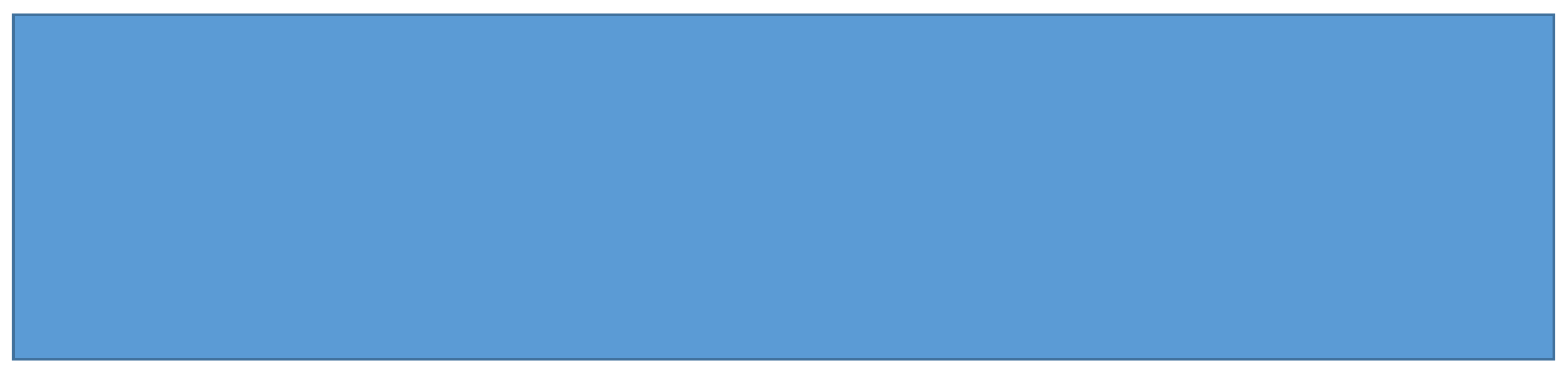




\section{APPENDIX 3: Ethical Approval Letter}

TE WHARE WĀNANGA O TE ŪPOKO O TE IKA A MÃUI

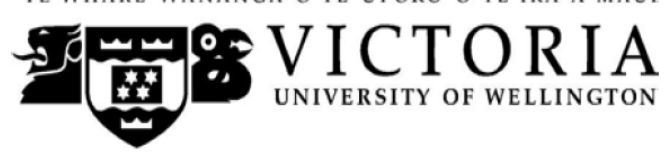

\begin{tabular}{lll} 
& Phone & $0-4-4635676$ \\
ME M O R N DU M & Fax & $0-4-4635209$ \\
\hline & Email & Allison.kirkman@vuw.ac.nz
\end{tabular}

\begin{tabular}{l|l}
\hline TO & Ashwina Naiker \\
\hline COPY TO & Kay de Vries \\
\hline FROM & Dr Allison Kirkman, Convener, Human Ethics Committee \\
\hline
\end{tabular}

\begin{tabular}{l|l}
\hline DATE & 27 June 2014 \\
\hline PAGES & 1 \\
\hline
\end{tabular}

SUBJECT Ethics Approval: 20994

Looking at lived experiences of being a hundred years and over

Thank you for your application for ethical approval, which has now been considered by the Standing Committee of the Human Ethics Committee.

Your application has been approved from the above date and this approval continues until 1 March 2016. If your data collection is not completed by this date you should apply to the Human Ethics Committee for an extension to this approval.

Best wishes with the research.

Allison Kirkman

Human Ethics Committee 


\section{APPENDIX 4: Participants Consent Form}

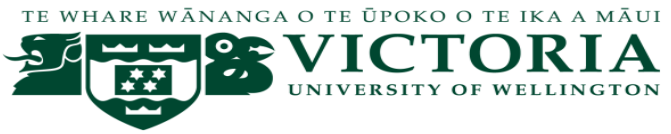

\section{Consent Form}

\section{Looking at Lived Experiences of being a Hundred Years and Over}

Principal Investigator: Ashwina Naiker

I have been provided with information about this research and have had the opportunity to ask questions and seek clarity regarding this study. I understand that I can ask any further questions regarding this research at any time.

I am aware that taking part in this study is voluntary and that I have the right to withdraw from the study at any time and up to two weeks after the interviews have been conducted.

I am aware that all information provided by me will be kept confidential at all stages of the study and that information will only be accessible to the principal researcher and her supervisor. All information used for the purpose of the thesis and publication material will not use my name and that no opinion will be attributed to me in any way that will identify me.

I understand that all information such as audio tape recordings will be destroyed after the study has been completed.

Please circle either yes or no

I consent to taking part in the interview

Yes No

I consent to the interview being audio taped

Yes No

I understand that I have the right to ask for the tape recorder to be turned off at any time during the interview

Yes No

I understand that taking part in the interview is voluntary and that I can withdraw anytime and up to two weeks after the interview have been conducted Yes No I would like a summary of the overrall research results Yes No 
Address for the summary of results to be sent to

I

(full name) hereby consent to take part in this study.

Signature Date 


\section{APPENDIX 5: Interview Protocol}

\section{INTERVIEW QUESTIONS AND PROMPTS}

Introduce self

Go over the information sheet and answer any questions that they may have about the study

Ensure consent form is signed, collect address details if participants want the research results.

Can you tell me what does it feel like to turn a hundred and how has this lived experience changed or affected the way you see yourself and others?

How has the following contributed to their experience of being a hundred years and over

- Lifestyle choices

- Community

- Environment

- Family

- Friends

- Religion

- Spirituality

- Personality

- Resilience

- Health

- Social factors

- Cultural factors

- Support systems/ services

- Relationships

- Achievements and goal setting

- Nutrition and hydration

- What was it like getting the Queens letter and other forms of recognition of longevity?

- go through the notes and ask questions that may need further exploration 
- Is there anything else that you feel you would like to share about your experience of turning a hundred?

Thank the participant for their time and ask if they would be happy to receive a phone call or meet me again if I had any further questions. 


\section{APPENDIX 6: Summary of Colaizzi's (1978) Method of Data Analysis}

\begin{tabular}{|c|c|c|}
\hline \multicolumn{2}{|r|}{ Steps in Analysis } & Purpose \\
\hline & Reading and re-reading description & To acquire general feeling for experience \\
\hline 2. & Extracting significant statements & $\begin{array}{l}\text { To generate information pertaining directly to phenomenon } \\
\text { studied }\end{array}$ \\
\hline 3. & Formulating meanings phenomenon & To illuminate meanings hidden in various contexts of the \\
\hline 4. & $\begin{array}{l}\text { Categorizing into cluster of themes and } \\
\text { validating with original text }\end{array}$ & To identify experiences common to all informants \\
\hline 5. & Describing & To generate a prototype of theoretical model \\
\hline & Returning to participants & To validate findings \\
\hline & Incorporating any changes based on the & $\begin{array}{l}\text { To present theoretical model that comprehensively reflects } \\
\text { the universal features of phenomenon }\end{array}$ \\
\hline
\end{tabular}

Appendix 6: Colaizzi's Stages (adapted from: Wojnar \& Swanson 2007). 


\section{APPENDIX 7: Transcriber Confidentiality Form}

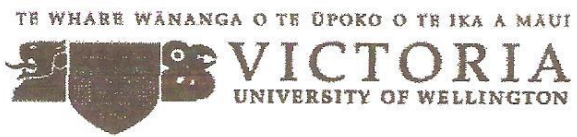

Confidentiality Agreement for Transcriber

Lived Experience of being a 100 years and over

Researcher: Ashwina Ashmala Naiker

Supervisor: Dr. Kay De Vries

My role as the research transcriber has been outlined to me by the researcher.

At all times the research information (tapes and transcripts) will be inaccessible to other persons.

Most importantly, I understand and agree to keep the information I hear and type in the course of transcribing confidential to the researcher and myself.

Transcriber Agreement Study Approved 15/01/15 


\section{APPENDIX 8: An Example of Data Analysis and Coding}

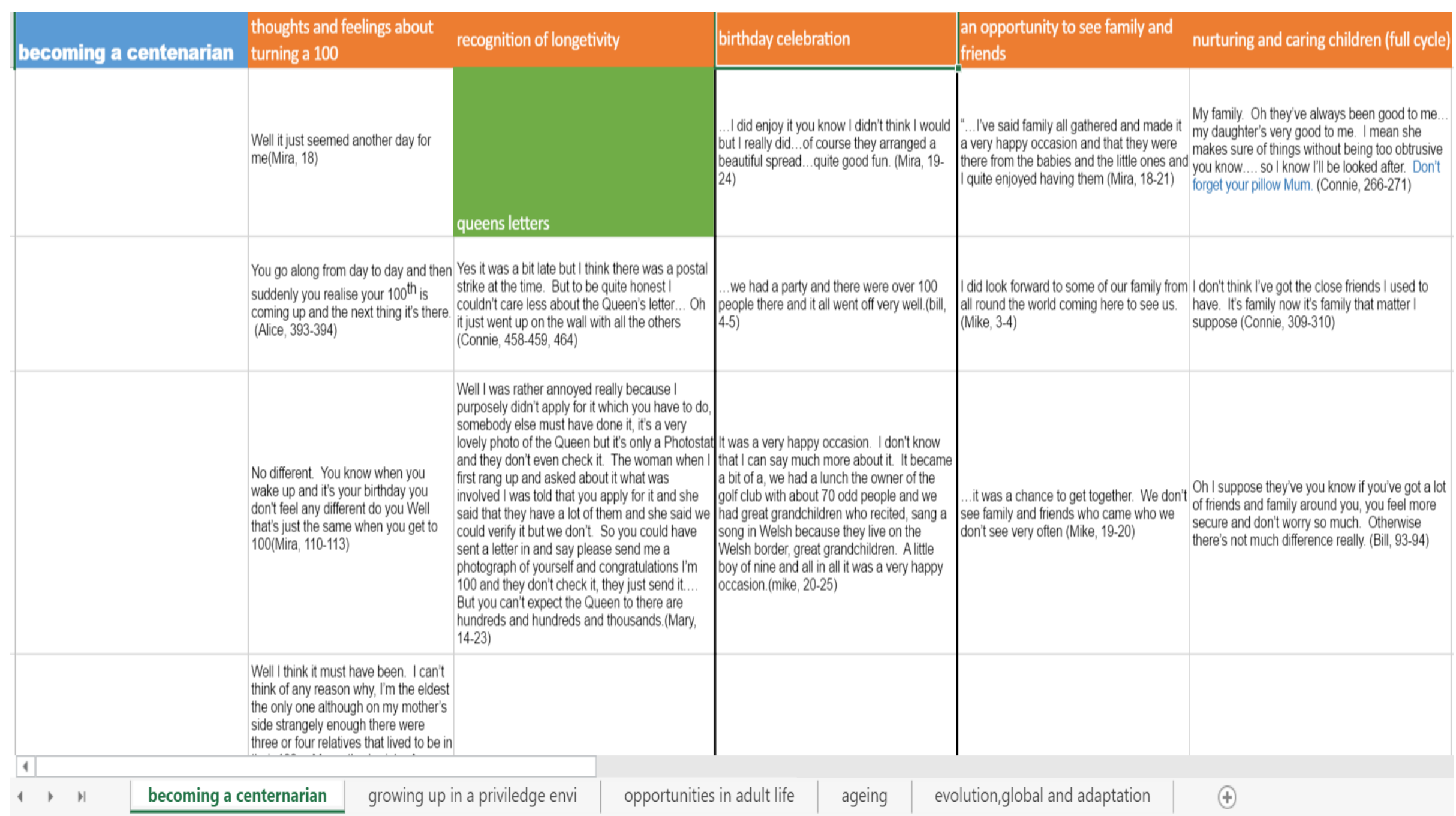




\section{APPENDIX 9: Participant Demographics}

Pseudonyms names have been used to protect participant's identity.

\begin{tabular}{|c|c|c|c|c|c|c|c|c|}
\hline $\begin{array}{l}\text { PARTICIPAN } \\
\text { TS }\end{array}$ & GENDER & $\begin{array}{l}\text { AGE AT TIME OF } \\
\text { INTERVIEW }\end{array}$ & $\begin{array}{l}\text { POSTION } \quad \mathbb{N} \\
\text { FAMILY }\end{array}$ & $\begin{array}{l}\text { PARENTS } \\
\text { OCCUPATION }\end{array}$ & $\begin{array}{l}\text { COUNTRY OF } \\
\text { BIRTH }\end{array}$ & CAREER & $\begin{array}{l}\text { MARTAL } \\
\text { STATUS }\end{array}$ & $\begin{array}{l}\text { NO OF LIVE } \\
\text { BIRTHS }\end{array}$ \\
\hline Mira & Female & 100 & $4^{\text {th }}$ child & Farmer & New Zealand & Shorthand typist & Married & 2 \\
\hline Bill & Male & 100 & Oldest & $\begin{array}{l}\text { Engineer/ } \\
\text { Farmer }\end{array}$ & Canada & Lawyer & Married & 4 \\
\hline Connie & Female & 100 & Oldest & $\begin{array}{l}\text { Children's } \\
\text { nurse }\end{array}$ & England & Accountant & Married & 2 \\
\hline Mike & Male & 100 & $3 r d$ & Farmer & New Zealand & Engineer/Businessman & Married & 3 \\
\hline Helen & Female & 100 & youngest & Farmer & New Zealand & Shorthand typist & Married & 2 \\
\hline Mary & Female & 100 & Oldest & Banker & Australia & $\begin{array}{l}\text { Kindergarten teacher, } \\
\text { Office worker, } \\
\text { Businesswoman }\end{array}$ & Single & 0 \\
\hline Wini & Female & 100 & Oldest & Tailor & New Zealand & Nun & Single & 0 \\
\hline Alice & Female & 100 & Oldest & $\begin{array}{l}\text { Shopkeeper/ } \\
\text { Businessman }\end{array}$ & New Zealand & Shorthand typist & Married & 2 \\
\hline Joy & Female & 106 & Oldest & Tailor & New Zealand & $\begin{array}{l}\text { Worked in her father's } \\
\text { general store }\end{array}$ & Married & 2 \\
\hline Kiryl & Male & 100 & Youngest & Businessman & England & Policeman, Businessman & Married & 2 \\
\hline
\end{tabular}




\section{REFERENCES}

Barzilai, N., Atzmon, G., Schechter, C., Schaefer, E. J., Cupples, A. L., Lipton, R., ... \& Shuldiner, A. R. (2003). Unique lipoprotein phenotype and genotype associated with exceptional longevity. Journal of the American Medical Association, 290(15), 2030-2040. doi:10.1001/jama.290.15.2030

Bornat, J. (2008). Biographical methods. In P. Alasuutari, L. Bickman, \& J. Brannen (Eds.), The SAGE handbook of social research methods (pp. 344-357). London: SAGE publications Ltd. doi:10.4135/9781446212165.n1

Braun, V., \& Clarke, V. (2006). Using thematic analysis in psychology. Qualitative Research in Psychology, 3(2), 77-101. doi:10.1191/1478088706qp063oa

Bryman, A. (2008). The end of the paradigm wars?. In P. Alasuutari, L. Bickman, \& J. Brannen (Eds.). The SAGE handbook of social research methods. (pp. 13-26). London: SAGE publication Ltd. doi:10.4135/9781446212165.n1

Byrne, M. M. (2001). Evaluating the findings of qualitative research. Association of Operating Room Nurses. Association of periOperative Registered Nurses (AORN) Journal, 73(3), 703-706. doi:10.1016/S0001-2092(06)61966-2

Carolan, M. (2003). Reflexivity: A personal journey during data collection. Nurse Researcher, 10(3), 7-14. doi:10.7748/nr2003.04.10.3.7.c5892

Cesarone, B. (1999). ERIC/EECE report: fostering the resilience of children. Childhood Education, 75(3), 182-184. doi:10.80/00094056.1999.10522011 
Chamberlayne, P., Bornat, J., \& Wengraf, T. (Eds.). (2000). The turn to biographical methods in social science. doi:10.4324/9780203466049

Chamberlyne, P., \& King, A. (2000). Cultures of care: Biographies of carers in Britain and the two Germanies. Bristol: The Policy Press.

doi:10.1332/policypress/9781861341662.001.0001

Chen, C. (2003). Revisiting the disengagement theory with differentials in the determinants of life satisfaction. Social Indicators Research, 64(2), 209-224. doi:10.1023/a:1024718321860

Clare, L., Rowlands, J., Bruce, E., Surr, C., \& Downs, M. (2008). The experience of living with dementia in residential care: an interpretative phenomenological analysis. The Gerontologist 48(6), 711-720. doi: 10.1093/geront/48.6.711

Colaizzi, P. (1978). Psychological research as the phenomenologist views it. In R. Valle, \& M. King (Eds.). Existential-phenomenological alternatives for psychology. New York: oxford university press. (p. 48-71). doi:10.1007/978-1-4615-6989-3_1

Corbally, M., \& O'Neill, C. S. (2014). An introduction to the biographical narrative interpretive method. Nurse Researcher, 21(5), 34-39.

doi:10.7748/nr.21.5.34.e1237

Cote, J. E., \& Levine, C. (1987). A formulation of Erikson's theory of ego identity formation. Developmental Review, 7, 273-325. doi:10.1016/02732297(87)90015-3

Creswell, J. W. (2007). Qualitative inquiry and research design: Choosing among five approaches. Thousand Oaks, CA: SAGE Publications. 
Creswell, J. W. (2009). Research Design: Qualitative, Quantitative and Mixed Methods Approaches. California, United States of America: SAGE publications. Inc.

Crosnoe, R., \& Elder Jr., G. H. (2002). Successful adaptation in the later years: A life course approach to aging. Social Psychology Quarterly, 65(4), 309-328. doi:10.2307/3090105

Cumming, E., Dean, L. R., Newell, D. S., \& McCaffrey, I. (1960). Disengagement - A tentative theory of aging. Sociometry, 23(1), 23-35. doi:10.2307/2786135

Cumming, E., \& Henry, W. E. (1961). Growing old: The process of disengagement. New York: Basic Books

Cumming, E. (1963). Further thoughts on the theory of disengagement. International Social Science Journal, XV(3), 377-393. Retrieved on 23 May 2016 from http://unesdoc.unesco.org/images/0001/000173/017381eo.pdf

Davenhill, R. (Ed.). (2007). Looking into later life: A psychoanalytic approach to depression and dementia in old age. London: Karnac Books.

Denscombe, M. (2010). The good research guide: For small-scale research projects. Maidenhead, England: Open University Press.

Dickson, A., Allan, D., \& O'Carrol, R. (2008). Biographical disruption and the experience of loss following spinal cord injury: An interpretative phenomenological analysis. Psychology and Health, 23(4), 407-425. doi: 10.1080/14768320701219136 
Doyle, S. (2012). Reflexivity and the capacity to think. Qualitative Health Research,23(2), 248-255. doi:10.1177/1049732312467854

Dulin, P. L., Stephens, C., Alpass, F., Hill, R. D., \& Stevenson, B. (2011). The impact of socio-contextual, physical and lifestyle variables on measures of physical and psychological wellbeing among Māori and non-Māori: The New Zealand Health, Work and Retirement study. Ageing and Society, 31(8), 1406-1424. doi:10.1017/s0144686x10001479

Elo, I. T., \& Preston, S. H. (1996). Education differentials in mortality: United States, 1979-85. Social Science Med, 42(1), 47-57. doi:10.1016/0277-9536(95)00062-3

Encyclopaedia Britannica. (n.d). World War II. Retrieved on 02 December 2015 from http://www.britannica.com/event/World-War-II

Erikson, E. H. (1950). Childhood and society. United States of America: W. W.Norton \& Company, Inc.

Erikson, E. H. (2nd Ed.). (1963). Childhood and society. United States of America: W. W. Norton \& Company, Inc.

Erikson, E. H. (1968). Identity youth \& crisis. England: Faber and Faber Limited.

Erikson, H. E. (1982). The life cycle completed. New York: W. W. Norton \& Company, Inc.

Erikson's stage theory in its final version. (n.d). Retrieved on 20 May 2016 from http://www.intropsych.com/ch11 personality/11eriksonstages.jpg 
Eskes, T., \& Haanen, C. (2007). Why do women live longer than men?. European Journal of Obstetrics \& Gynaecology and Reproductive Biology, 133, 126-133. doi:10.1016/j.ejogrb.2007.01.006

Evert, J., Lawler, E., Bogan, H., \& Perls, T. (2003). Morbidity profiles of centenarians: Survivors, delayers, and escapers. Journal of Gerontology, 58A(3), 232-237. doi:10.1093/gerona/58.3.m232

Finlay, L. (2009). Exploring lived experience: Principles and practices of phenomenological research. International Journal of Therapy and Rehabilitation, 16(9), 474- 481. doi:10.12968/ijtr.2009.16.9.43765

Franceschi, C., Motta, L., Valensin, S., Rapisarda, R., Franzone, A., Berardelli, M., ... Baggio, G. (2000). Do men and women follow different trajectories to reach extreme longevity? Aging Clin Exp Res, 12(2), 77-84. doi:10.1007/bf03339894

Fraser, G. E., \& Shavlik, D. J. (2001). Ten years of life. Archives Internal Medicine, 161(3), 1645-1652. doi:10.1001/archinte.161.13.1645

Freeman, S., Garcia, J., \& Martson, H. R. (2013). Centenarian self-perception of factors responsible for attainment of extended health and longevity. Educational Gerontology, 39(10), 717-728. doi:10.1080/03601277.2012.750981

Fries, J. F. (1980). Aging, natural death, and the compression of morbidity. The New England Journal of Medicine, 303(3), 245-250. doi:10.1056/nejm198007173030304

Gagnon, A., \& Bohnert, N. (2012). Early life socioeconomic conditions in rural areas and old-age mortality in twentieth-century Quebec. Social Science \& Medicine, 75(8), 1497-1504. doi:10.1016/j.socscimed.2012.06.007 
Geesaman, B. J., Benson, E., Brewster, S. J., Kunkel, L. M., Blanche, H., Thomas, G., ... Puca, A. A. (2003). Haplotype-based identification of a microsomal transfer protein marker associated with the human lifespan. Proceedings of the National Academy of Sciences, 100(24), 14115-14120. doi:10.1073/pnas.1936249100

Grix, J. (2002). Introducing students to the generic terminology of social research. Politics, 22(3), 175-186. doi:10.1111/1467-9256.00173

Gruenberg, E. M., Brandon, S., \& Kasius, R. V. (1966). Identifying cases of the social breakdown syndrome. The Milbank Memorial Fund Quarterly, 44(1), 150-155. doi: $10.2307 / 3349077$

Haight, B. (2001). Sharing life stories: Acts of intimacy. Generations, 25(2), 90-92.

Havighurst, R. J., \& Albrecht, R. (1953). Older people. New York, United States of America: Longmans, Green and Co., Inc.

Havighurst, R. J. (1948). Developmental tasks and education. New York: McKay.

Helmuth, L. (2003). The wisdom of the wizened. Science, New Series: American Association for the Advancement of Science, 299(5611), 1300-1302. doi:10.1126/science.299.5611.1300

Hensley, B., Martin, P., Margrett, J. A., MacDonald, M., Siegler, I. C., \& Poon, L. W. (2012). Life events and personality predicting loneliness among centenarians: Findings from the Georgia centenarian study. The Journal of Psychology, 146(12), 173-188. doi:10.1080/00223980.2011.613874 
Hergenhahn, B. R. (1994). An Introduction to theories of personality (4th ed.).

Englewood Cliffs, NJ: Prentice-Hall.

Hollway, W., \& Jefferson, T. (2000). Biography, anxiety and the experience of locality. In P. Chamberlayne, J. Bornat, \& T. Wengraf (Eds.). The Turn of Biographical Methods in Social Science. London: Routledge. doi:10.4324/9780203466049

Huang, C., \& Elo, I. T. (2009) Mortality of the oldest old Chinese: The role of early-life nutritional status, socio-economic conditions, and sibling sex-composition. Population Studies, 63(1), 7-20. doi:10.1080/00324720802626921

Hudson, M. L., \& Russell, K. (2009). The treaty of waitangi and research ethics in Aotearoa. Bioethical Inquiry, 6, 61-68. doi:10.1007/s11673-008-9127-0

Hutnik, N., Smith, P., \& Koch, T. (2012). What does it feel like to be 100 ? Socioemotional aspects of well-being in the stories of 16 centenarians living in the United Kingdom. Aging and Mental Health, 16(7), 811-818. doi:10.1080/13607863.2012.684663

Ingham-Bloomfield, R. (2014). A nurse's guide to quantitative research. Australian Journal of Advance Nursing, 32(2), 32-38.

Jacob, S. A., \& Furgerson, S. P. (2012). Writing interview protocols and conducting interviews: Tips for students new to the field of qualitative research. The Qualitative Report, 17(T\&L Art, 6), 1-10. Retrieved on 11 March 2016 from http://www.nova.edu/ssss/QR/QR17/jacob.pdf 
John, R. (1984). Prerequisites of an adequate theory of ageing: A critique and reconceptualization. Mid-American Review of Sociology, 9 (2), 79-108. doi:10.17161/str.1808.4968

Jones, K. (2002). The turn to a narrative knowing of persons: One method explored. Journal of Research in Nursing, 8(1), 60-71. doi:10.1177/136140960300800109

Johnson, C., \& Barer, B. M. (1992). Patterns of engagement and disengagement among the oldest of old. Journal of Aging Science, 6(4), 351-364. doi:10.1016/0890-4065(92)90017-z

Kim, J. I. (2013). Social factors associated with centenarian rate (CR) in 32 OECD countries. BMC International Health and Human Rights, 13(1), 16. doi:10.1186/1472-698x-13-16

Kvale, Steiner. (2007). Doing interviews. Thousand Oaks: Sage.

Kvale, S., \& Brinkman, S. (2009). Interviews: Learning the craft of qualitative research interviewing $\left(2^{\text {nd }}\right.$ ed. $)$. Thousand Oaks: Sage.

Longevity. (n.d). In Merriam-Webster's online dictionary. Retrieved May 17, 2016, from http://www.merriam-webster.com/medical/longevity

Lupien, J. S., \& Wan, N. (2004). Successful ageing: From cell to self. Philosophical Transactions: Biological Sciences, 359(1449), 1413-1426.

doi:10.1098/rstb.2004.1516 
Ljungquist, B., Berg, S., Lanke, J., McClearn, G. E., \& Perdesen, N. L. (1998). The effect of genetic factors for longevity: A comparison of identical and fraternal twins in the Swedish twin registry. The Journals of Gerontology Series A: Biological Sciences and Medical Sciences, 53A(6), 441-446. doi:10.1093/gerona/53a.6.m441

Magnolfi, S. U., Petruzzi, E., Pinzani, P., Malentacchi, F., Pazzagli, M., \& Antonini, F. M. (2007). Longevity index (LI\%) and centenarity index (Cl\%): New indicators to evaluate the characteristics of aging process in the Italian population. Archives of Gerontology and Geriatrics, 44(3), 271-276. doi:10.1016/j.archger.2006.05.006

Magnolfi, S. U., Noferi, I., Petruzzi, E., Pinzani, P., Malentacchi, F., Pazzagli, M., ...\& Marchionni, N. (2009). Centenarians in Tuscany: The role of the environmental factors. Archives of Gerontology and Geriatrics, 48(2), 263-266. doi:10.1016/j.archger.2008.02.002

McCusker, K., \& Gunaydin, S. (2015). Research using qualitative, quantitative or mixed methods and choice based on the research. Perfusion, 30(7), 537-542. doi:10.1177/0267659114559116

Mellon, N. (1998). The art of storytelling. Rockport, MA: Element Inc.

Merriam, S. B., Courtenay, B. C., \& Reeves, P. M. (1997). Ego development in the face of death: How being HIV positive affects movement through Erikson's adult stages of development. Journal of Adult Development, 4(4), 221-235. doi:10.1007/bf02511413

Miller, L. S., Mitchell, M. B., Woodard, J. L., Davey, A., Martin, P., \& Poon, L. W. (2010). Aging, Neuropsychology, and Cognition, 17(5), 575-590. doi:10.1080/13825585.2010.481355 
Miller-Lewis, L., Searle, A. K., Sawyer, M. G., Baghurst, P. A., \& Hedley, D. (2013). Resource factors for mental health resilience in early childhood: An analysis with multiple methodology. Child and adolescent psychiatry \& mental health, 7(1), 6. doi:10.1186/1753-2000-7-6

Ministry of Health. (2014). The guide to He Korowai Oranga: Māori health strategy 2014. Wellington: Ministry of Health. Retrieved on 18 May 2016 from http://www.health.govt.nz/our-work/populations/maori-health/he-korowai-oranga

Ministry of Health. (2016). New Zealand Health Strategy: Future direction. Wellington: Ministry of Health. Retrieved on 18 May 2016 from http://www.health.govt.nz/publication/new-zealand-health-strategy-2016

Ministry of Health. (2015). Tatau Kahukura: Māori Health Chart Book 2015 (3 $3^{\text {rd }}$ ed.). Wellington: Ministry of Health. Retrieved on 18 May 2016 from http://www.health.govt.nz/publication/tatau-kahukura-maori-health-chart-book2015-3rd-edition

Museum of New Zealand Te Papa Tongarewa. (n.d). International relations. Retrieved on 20 December 2015 from http://sites.tepapa.govt.nz/sliceofheaven/web/html/worldwarii.html

Museum of New Zealand Te Papa Tongarewa. (n.d). Social welfare \& the state. Retrieved on 20 December 2015 from http://sites.tepapa.govt.nz/sliceofheaven/web/html/greatdepression.html

Nilsen, A. (2008). From questions of methods to epistemological issues: The case of biographical research. In P. Alasuutari, L. Bickman, \& J. Brannen (Eds.), The SAGE handbook of social research methods. (pp. 81-95). London: SAGE Publications Ltd. 
Patterson, A. C., \& Veenstra, G. (2010). Loneliness and risk of mortality: A longitudinal investigation in Alameda country, California. Social Science \& Medicine, 7(1), 181-186. doi:10.1016/j.socscimed.2010.03.024

Perls, T., Kunkel, L. M., \& Puca, A. A. (2002). The genetics of exceptional longevity. The Journal of American Geriatrics Society, 50(2), 359-368. doi:10.1046/j.15325415.2002.49283.x

Perls, T., Wilmoth, J., Levenson, R., Drinkwater, M., Cohen, M., Bogan, H., . . Puca, A. (2002). Life-long sustained mortality advantage of siblings of centenarians. Proceedings of the National Academy of Sciences of the United States of America, 99(12), 8442-8447. doi:10.1073/pnas.122587599

Perls, T., \& Terry, D. (2003). Understanding in the determinants of exceptional longevity. Annals of Internal Medicine, 139(5_Part_2), 445. doi:10.7326/00034819-139-5_part_2-200309021-00013

Perl, T. (2007). The familiality of exceptional longevity. In L. W. Poon, \& T. T. Perls (Eds.), Annual review of gerontology \& geriatrics volume: Biopsychosocial approaches to longevity, 27 (pp. 63-79). New York: Springer Publication Company, LLC

Preston, S. H., Hill, M. E., \& Drevenstedt, G. L. (1998). Childhood conditions that predict survival to advanced ages among African-Americans. Social Science \& Medicine, 47(9), 1231-1246. doi:10.1016/s0277-9536(98)00180-4

Privilege. (n.d.). In Merriam-Webster's online dictionary. Retrieved May 18, 2016, from http://www.merriam-webster.com/dictionary/privilege 
Puca, A. A., Daly, M. J., Brewster, S. J., Matise, T. C., Barrett, J., Shea-Drinkwater, M., ... Perls, T. (2001). A genome-wide scan for linkage to human exceptional longevity identifies a locus on chromosome 4. Proceedings of the National Academy of Sciences, 98(18), 10505-10508. doi:10.1073/pnas.181337598

Rahman-Filipiak, A., Woodard, J. L., Stephen Miller, L., Martin, P., Davey, A., \& Poon, L. W. (2015). Octogenarian and centenarian performance on the Fuld Object Memory Evaluation. Aging, Neuropsychology, and Cognition, 22(4), 438-451. doi:10.1080/13825585.2014.968085

Ramdhan, N. L. D. S. (2010). Child development in war-torn countries and Erik Erikson psychosocial theory of human development. (Doctoral dissertation). Long Island University, The Brooklyn Center, New York: United States. Retrieved on 16 December, 2015 from http://search.proquest.com/docview/749402849/

Ramvi, E. (2015). I am only a nurse: A biographical narrative story of a nurse's selfunderstanding and its implication for practice. BioMed Central Nursing, 14(1), 2331. doi:10.1186/s12912-015-0073-y

Randall, G. K., Martin, P., McDonald, M., \& Poon, L. W. (2010). Social resources and longevity: Findings from the Georgia centenarian study. Gerontology, 56(1), 106111. doi:10.1159/000272026

Read, S., Braam, A. W., Lyyra, T-M., \& Deeg, D. J. H. (2014). Do negative life events promote gerotranscendence in the second half of life?. Aging \& Mental Health, 18(1), 117-124. doi:10.1080/13607863.2013.814101 
Reed. T., Dick. D. M., Uniacke. S. K., Foroud. T., \& Nichols. W. C. (2004). Genome wide scan for healthy aging phenotype provides support for a locus near D4S1564 promoting healthy aging. The Journals of Gerontology Series A: Biological Sciences and Medical Sciences. 59A(3). 227-232. doi:10.1093/gerona/59.3.b227

Robine, J., \& Vaupel, J. W. (2001). Supercentenarians: Slower ageing individuals or senile elderly? Experimental Gerontology, 36(4-6), 915-930. doi:10.1016/s05315565(00)00250-3

Robine, J., \& Allard, M. (1998). The Oldest Human. Science, 279(5358), 1834-1835. doi:10.1126/science.279.5358.1831h

Rosenthal, G. (1993). Reconstruction of life stories: Principles of selection in generating stories for narrative biographical interviews. The Narrative Study of Lives, 1, 59-91. Retrieved on 15 November 2016 from http://www.ssoar.info/ssoar/bitstream/handle/document/5929/ssoar-tnsl-1993-1rosenthal-reconstruction of life stories.pdf?sequence $=1$

Rosenthal, G. (2003). The healing effects of storytelling: On the conditions of curative storytelling in the context of research and counseling. Qualitative Inquiry, 9(6), 915-933. doi:10.1177/1077800403254888

Ross, C., \& Moore, S. (2014). Utilising biographical narrative interpretive methods: rich perspectives on union learning journeys and learner motivations. Journal of Education and Work, 29(4), 450-469. doi:10.1080/13639080.2014.978273. 
Rothera, I. C., Jones, R., Harwood, R., Avery, A. J., \& Waite, J. (2002). Survival in a cohort of social services placement in nursing and residential homes: Factors associated with life expectancy and mortality. Public Health, 116(3), 160-165. doi: 10.1038/sj.ph.1900832

Sachdev, P. S., Levitan, C., Crawford, J., Sidhu, M., Slavin, M., Richmond, R., ... Mather, K. A. (2013). The Sydney centenarian study: Methodology and profile of centenarians and near-centenarians. International Psychogeriatrics, 25(6), 9931005. doi:10.1017/s1041610213000197

Sadler, G. R., Lee, H.-C., Lim, R. S.-H., \& Fullerton, J. (2010). Recruitment of hard-toreach population subgroups via adaptations of the snowball sampling strategy. Nursing \& Health Sciences, 12(3), 369-374. doi:10.1111/j.14422018.2010.00541.x

Sarantakos, S. (1993). Social Research. London: The Macmillan Press Ltd

Schroots, J. J. F. (1996). Theoretical developments in the psychology of aging. The Gerontologist, 36(6), 742-748. doi:10.1093/geront/36.6.742

Schächter, F., Faure-Delanef, L., Guénot, F., Rouger, H., Froguel, P., Lesueur-Ginot, L., \& Cohen, D. (1994). Genetic associations with human longevity at the APOE and ACE loci. Nature Genetics, 6(1), 29-32. doi:10.1038/ng0194-29

Schwartz, J. E., Friedman, H. S., Tucker, J. S., Tomlinson-Keasey, C., Wingard, D. L., \& Criqui, M. H. (1995). Sociodemographic and psychosocial factors in childhood as predictors of adult mortality. American Journal of Public Health, 85(9), 12371245. doi:10.2105/ajph.85.9.1237 
Sebastiani, P., \& Perls, T. T. (2012). The genetics of extreme longevity: Lessons from the New England centenarian study. Frontiers in Genetics, 3(277), 1-7. doi:10.3389/fgene.2012.00277

Silverstein, M., Bengtson, V. L., Putnam, M., Putney, N. M., \& Gans, D. (Eds). (2009). Handbook of Theories of Aging. New York: Springer Publishing Company, LLC.

Skytte, A., Pedersen, N. L., Kaprio, J., Stazi, M. A., Hjelmborg, J. v.B., Lachine, I., ... Christensen, K. (2003). Longevity studies in genomEUtwin. Twin Research, 6(5), 448- 454. doi:10.1375/136905203770326457

Smith, R. K., Mineau, P. G., Garobotti. G., \& Kerber, R. (2009). Effects of childhood and middle- adulthood family conditions on later life mortality: Evidence from the Utah population database, 1850-2002. Social Science \& Medicine, 68(8), 16491658. doi:10.1016/j.socscimed.2009.02.010.

Statistics New Zealand. (2012). Demographic trends. Retrieved on 13 May 2016 from http://www.stats.govt.nz/browse for stats/population/estimates and projections/ demographic-trends-2012.aspx

Statistics New Zealand. (2013). 2013 census totals by topic. Retrieved on 13 May 2016 from http://www.stats.govt.nz/Census/2013-census/data-tables/total-bytopic.aspx

Stephen Miller, L., Mitchell, M. B., Woodard, J. L., Davey, A., Martin, P. M., \& Poon, L. W (2010). Cognitive performance in centenarians and the oldest old: Norms from the Georgia centenarian study. Aging, Neuropsychology and Cognition, 17(5), 575-590. doi:10.1080/13825585.2010.481355 
Svetina, M. (2014). Resilience in the context of Erikson's theory of human development. Current Psychology, 33(3), 393-404. doi:10.1007/s12144-0149218-5

Tatauranga Aotearoa Statistics New Zealand. (n.d). The average life expectancy for males is six years less than for females. Retrieved on19 May 2016 from http://www.stats.govt.nz/browse for stats/population/mythbusters/males-lifeexpectancy-lower.aspx

Terblanche, W. (2015). Alternative state and national projections of Australia's very elderly population. Journal of Population Research, 32(3-4), 187-213. doi:10.1007/s12546-015-9149-5

Terblanche, W. (2015). Explaining the substantial growth of centenarian population in Australia's states, 1981 to 2012. Journal of Population Research, 32(2), 81-93. doi:10.1007/s12546-015-9143-y

Thomas, L. E., \& Eisenhandler, S. A. (Eds.). (1994). Aging and the religious dimension. Westport, Connecticut, London: Auburn House.

Tornstam, L. (1989). Gero-transcendence: A reformulation of the disengagement theory. Aging Clinical and Experimental Research, 1(1), 55-63. doi:10.1007/bf03323876

Tornstam, L. (1994). Gerotranscendence: A theoretical and empirical exploration. In L.Thomas, \& S. A. Eisenhandler (Eds.). Aging and the religious dimension. (pp. 203-225). Greenwood: Westport. 
Tornstam, L. (2005). Gerotranscendence: A developmental theory of positive aging. New York: Springer Publishing Company Inc.

Tornstam, L. (1997). Gerotranscendence: The contemplative dimension of aging. Journal of Aging Studies, 11(2), 143-154. doi:10.1016/s0890-4065(97)90018-9

Tornstam, L. (2011). Maturing into gerotranscendence. Journal of Transpersonal Psychology, 43(2), 166-180. Retrieved from

http://search.proquest.com.helicon.vuw.ac.nz/docview/1010377448?accountid=1 4782

Turner, D. W., III (2010). Qualitative interview design: A practical guide for novice investigators. The Qualitative Report, 15(3), 754-760. Retrieved on 11 February 2016 from http://www.nova.edu/ssss/QR/QR15-3/qid.pdf

U.S. Department of Health and Human Services, National Institute on Aging, National Institutes of Health. (2011). Global Health and Aging (NIH Publication No. 117737). Retrieved on 20 January 2016 from https://d2cauhfh6h4x0p.cloudfront.net/s3fspublic/global health and aging.pdf?q.52VK49USX58EJwZ3BjLI.yphsH2T h

Vajda, J. (2007). Two survivor cases: Therapeutic effect as side product of biographical narrative interview. Journal of Social Work Practice, 21(1), 89-102. doi:10.1080/02650530601173664

Vaupel, J. W. (1997). The remarkable improvements in survival at older ages. Philosophical Transactions of the Royal Society B: Biological Sciences, 352(1363), 1799-1804. doi:10.1098/rstb.1997.0164 
Vina, J., \& Borras, C. (2010). Women lived longer than men: Understanding molecular mechanism offers opportunities to intervene by using estrogenic compounds. Antioxidants \& Redox Signaling, 13(3), 269-278. doi:10.1089/ars.2009.2952

Vogel-Scibilia, S. E., McNulty, K. C., Baxter, B., Miller, S., Dine, M., \& Frese, F. J. (2009). The recovery process utilizing Erikson's stages of human development. Community Mental Health Journal, 45(6), 405-414. doi:10.1007/s10597-0099189-4

Wadensten, B., \& Carlsso, M. (2001). A qualitative study of nursing staff members' interpretations of signs of gerotranscendence. Journal of Advanced Nursing, 36(5), 635-642. doi:10.1046/j.1365-2648.2001.02019.x

Wadensten, B., \& Carlsso, M. (2002). Theory-driven guidelines for practical care of older people, based on the theory of gerotranscendence. Journal of Advanced Nursing, 41(5), 462-470. doi:10.1046/j.1365-2648.2003.02554.x

Wadensten, B. (2005). Introducing older people to the theory of gerotranscendence. Journal of Advanced Nursing, 52(4), 381-388. doi:10.1111/j.13652648.2005.03603.x

Wadensten, B., \& Carlsso, M. (2007). The theory of gerotranscendence in practice: Guidelines for nursing - Part II. International Journal of Older People Nursing, 2(4), 295-301. doi:10.1111/j.1748-3743.2007.00086.x

Wallace, J. B., \& Prevost, S. S. (2006). Two methods for predicting limited life expectancy in nursing homes. Journal of Nursing Scholarship, 38(2), 148-153. doi:10.1111/j.1547-5069.2006.00092.x 
Wang, K., Duan, G., Jia, H., Xu, E., Chen, X., \& Xie, H. (2015). The level and influencing factors of gerotranscendence in community-dwelling older adults. International Journal of Nursing Science, 2(2), 123-127. doi:10.1016/j.ijnss.2015.04.001

Wengraf, T. (2001). Qualitative research interviewing. London: SAGE publications Ltd.

Wengraf, T. (2004). Biological Narrative Interpretive Method (BNIM). Shortguide. Retrieved on 04 September 2016 from https://www.google.co.nz/?ion=1\&espv=2\#q=Wengraf\%2C+T.+(2004)

Wengraf, T. (2008). Biological Narrative Interpretive Method (BNIM): For researching lived experience and whole lives. A summary. Retrieved on 04 September 2016 from

https://www.google.co.nz/?ion=1\&espv=2\#q=Wengraf\%2C+T.+(2008).+Biologica I+Narrative+Interpretive+Method+(BNIM)\%3A+For+researching+lived+experienc e+and+whole+lives.+A+summary.

Willcox, D. C., Willcox, B. J., Wang, N-C., He, Q., Rosenbaum, M., \& Suzuki, M. (2008). Life at the extreme limit: Phenotypic characteristics of supercentenarians in Okinawa. The Journals of Gerontology Series A: Biological Sciences and Medical Sciences, 63A(11), 1201-1208. doi:10.1093/gerona/63.11.1201

Willcox, B. J., Willcox, D. C., He, Q., Curb, J. D., \& Suzuki, M. (2006). Siblings of Okinawan centenarians share lifelong mortality advantages. The Journals of Gerontology Series A: Biological Sciences and Medical Sciences, 61(4), 345354. doi:10.1093/gerona/61.4.345 
Wilson, S. A. (1997). The transition to nursing home life: A comparison of planned and unplanned admissions. Journal of Advanced Nursing, 26(5), 864-871. doi:10.1046/j.1365-2648.1997.00636.x

Wojnar, D. M \& Swanson, K. M (2007). Phenomenology an exploration. Journal of Holistic Nursing, 25(3), 172-180. doi:10.1177/0898010106295172.

Woodward, A., \& Blakely, T. (2016). The art of medicine: Nobody on the face of the globe lived longer. The Lancet, 387(10023), 1049-1050. doi:10.1016/s01406736(16)00667-x

World Health Organisation: Global Health Observatory data. (n.d). Life expectancy. Retrieved on 18 May 2016 from http://www.who.int/gho/mortality burden disease/life tables/situation trends tex t/en/

World Health Organisation. (2011). World health statistics. Retrieved on 18 May 2016 from http://www.who.int/gho/publications/world health statistics/EN WHS2011 Full.p $\underline{\mathrm{df}}$

World Health Organisation. (2015). Ageing and health (fact sheet no.404). Retrieved on 18 May 2016 from http://www.who.int/mediacentre/factsheets/fs404/en/

Yang, Z., Salvin, M. J., \& Sachdev, P. S. (2013). Dementia in the oldest of old. Nature Reviews: Neurology, 9(7), 382-393. doi:10.1038/nrneurol.2013.105 